\title{
Endometriosis: current challenges in modeling a multifactorial disease of unknown etiology
}

Helena Malvezzi ${ }^{{ }^{*}} \mathbb{0}$, Eliana Blini Marengo², Sérgio Podgaec ${ }^{1}$ and Carla de Azevedo Piccinato ${ }^{{ }^{*}}$

\begin{abstract}
Endometriosis is a chronic inflammatory hormone-dependent condition associated with pelvic pain and infertility, characterized by the growth of ectopic endometrium outside the uterus. Given its still unknown etiology, treatments usually aim at diminishing pain and/or achieving pregnancy. Despite some progress in defining mode-of-action for drug development, the lack of reliable animal models indicates that novel approaches are required. The difficulties inherent to modeling endometriosis are related to its multifactorial nature, a condition that hinders the recreation of its pathology and the identification of clinically relevant metrics to assess drug efficacy. In this review, we report and comment endometriosis models and how they have led to new therapies. We envision a roadmap for endometriosis research, integrating Artificial Intelligence, three-dimensional cultures and organ-on-chip models as ways to achieve better understanding of physiopathological features and better tailored effective treatments.
\end{abstract}

Keywords: Endometriosis, Animal model, Drug efficacy, Organ-on-chip, Cell culture, Artificial intelligence

\section{Background: setting and disease}

Endometriosis is a reproductive age-associated disease $[1,2]$ that has become the target of intense investigation, as indicated by the increasing number of scientific papers published. In the last 10 years, indeed, more than 75\% of endometriosis-related papers, appeared during that period according to Web of Science data. This surge of information directed to both laypersons and healthcare professionals improved the identification of symptoms, augmented the odds of correct diagnosis as well as the awareness of available medical treatment [3].

Worldwide epidemiological studies show a mean prevalence of $10 \%$ of endometriosis in the pre-menopausal population [4], with annual incidences in specific populations varying from $0.112 \%$ [5] to $0.72 \%$ [6]. The difficulties to reach the diagnosis comprise the need for clinical and surgical expertise to evaluate correctly the

\footnotetext{
*Correspondence: helenamalvezzi@gmail.com; cpiccinato@uwalumni.com

${ }^{1}$ Hospital Israelita Albert Einstein, São Paulo, SP 05652-900, Brazil

Full list of author information is available at the end of the article
}

clinical symptoms and to detect the presence of ectopic endometrial implants (so-called lesions) in the peritoneal cavity and on pelvic organs [7]. Although imaging methods such as transvaginal ultrasonography with bowel preparation and magnetic resonance are common diagnostic tools, the gold standard diagnostic method for endometriosis is still the histopathological analysis of lesions collected during laparoscopic surgery [8]. The etiopathogenesis of endometriosis is not known. However, there are theories on the origin of endometriotic lesions in the peritoneal cavity. It is proposed by some investigators that stem cells originating the lesions are already there in the peritoneal cavity whereas others propose that endometrium cells are seeded there by retrograde menstruation. The pathophysiology, however, is strongly influenced by other factors such as genetic predisposition and hormonal factors such as resistance to progesterone, estrogen dependence; inflammation, angiogenesis, and vascularization processes, oxidative stress, resistance to apoptosis and immunological factors are also involved to various degrees in lesion development (Fig. 1).

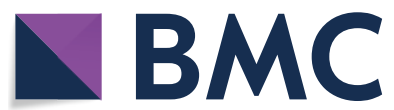

c) The Author(s) 2020. This article is licensed under a Creative Commons Attribution 4.0 International License, which permits use, sharing, adaptation, distribution and reproduction in any medium or format, as long as you give appropriate credit to the original author(s) and the source, provide a link to the Creative Commons licence, and indicate if changes were made. The images or other third party material in this article are included in the article's Creative Commons licence, unless indicated otherwise in a credit line to the material. If material is not included in the article's Creative Commons licence and your intended use is not permitted by statutory regulation or exceeds the permitted use, you will need to obtain permission directly from the copyright holder. To view a copy of this licence, visit http://creativeco mmons.org/licenses/by/4.0/. The Creative Commons Public Domain Dedication waiver (http://creativecommons.org/publicdomain/ zero/1.0/) applies to the data made available in this article, unless otherwise stated in a credit line to the data. 


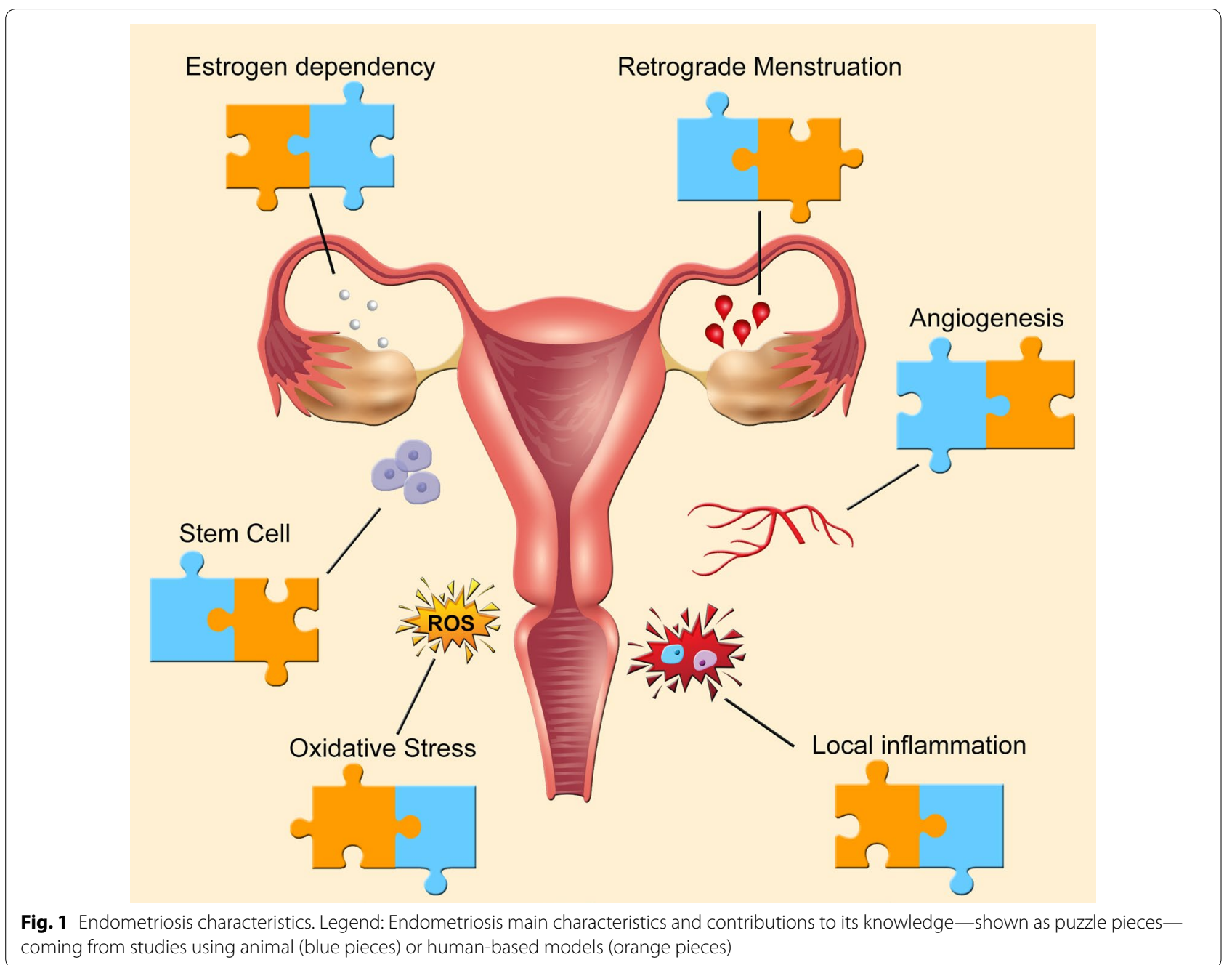

It is generally accepted that the lesions found in different pelvic sites are the main cause of all clinical findings in endometriosis. However, many women have lesions while being asymptomatic, and such lesions are found during abdominal surgery done for reasons other than endometriosis. The prevalence of asymptomatic cases among studies is highly variable ranging from 6\% [9] up to $43.3 \%[10,11]$. The common clinical symptoms associated with endometriosis vary from mild to severe pain and/or infertility. The pain observed in 30 to $80 \%$ of the cases can manifest itself as dysmenorrhea, acyclic pelvic pain, deep dyspareunia, dysuria and dyschezia [12]. Infertility is found in 30 to $40 \%$ of the cases [6]. Other symptoms are fatigue, diarrhea, constipation, bloating or nausea, mainly during menstrual periods, and painrelated to mental health problems such as somatization or depression, heightened sensitivity and anxiety are also seen in endometriosis patients when compared to control groups [13].
The treatment for endometriosis usually aims at ameliorating symptoms, mainly pain, and/or achieving pregnancy in infertile patients [14]. Early understanding of the disease has come from experimental studies in animals [15] while advances in the therapy of endometriosis have come from observation of symptomatic patients during surgery [16], from research on patients' data and from in vitro cell cultures [17].

\section{The challenge of modeling endometriosis}

Currently, the main approaches to investigate endometriosis are human-based either in vivo or in vitro, using cells or tissue samples. There are also experimental in vivo animal models [18]. The first type encompasses clinical trials, patients' observational and association studies. Experimental in vitro studies include histopathological comparative experiments, as well as tissue fragments, cells and fluids obtained from resected lesions or aspiration biopsies, in general called patient-derived tissue or 
fluid. In vivo animal models are still required to test drug candidates that affect these processes and to support preclinical trial testing.

The development of in vitro or in vivo models that recreate or exhibit the main characteristics of endometriosis is a challenging task for several reasons. Firstly, it is not known how the disease starts and how it persists. Secondly, endometriosis comprises distinctive disease features such as ovarian endometrioma, and peritoneal as well as deep infiltrative lesions. Lastly, endometriosis has not a single pathophysiological process on which basis it could be modeled. Indeed, being a multifactorial and complex disease, endometriosis has also been associated to environmental [19], genetic [20], immunological factors [21] and hormonal changes (such as estrogendependency [22] and progesterone resistance [23]).

The difficulties to evaluate and model the onset of endometriosis stem because it is not clear when it actually starts. It is accepted and reported that many women had already had the disease for up to 12 years before the appearance of symptoms [24]. The main mechanism put forward to explain the beginning of that disease is based on retrospective epidemiological studies [25]. They show that retrograde menstruation [16] is associated with endometrial implants attached to the peritoneal cavity, which would develop into endometrial lesions. However, almost all reproductive-age women (90\%) have retrograde menstruation to the pelvic cavity, but only $10 \%$ are actually affected by endometriosis. This suggests that other associated factors are needed, besides retrograde menstruation, for the onset and progression of the disease in the peritoneal cavity [26].

Thus, the main current challenge to develop research models for the investigation of endometriosis goes beyond the creation of models that fully recapitulate the multitude of factors affecting this disease; that challenge requires the definition of measurable and clinically translatable effective endpoints.

Generally speaking, there is still a gap in the development of adequate disease models to study essential biological processes [27], as shown by the fact that between 50 and $70 \%$ of drugs that reach phase II and III in clinical trials fail to demonstrate effectiveness [28, 29]. Particularly, an ideal model to investigate endometriosis should incorporate relevant disease characteristics, such as the same cellular pathways and the clinical behavior observed in patients.

Until now, the most common approach to this problem involved diverse animal models whose pathophysiological processes are claimed to be somehow similar to the human ones [30]. This idea relies on the concept that the use of animal models facilitates the analysis of integrative and complex events that occur in vivo. Some may claim that the biological systems in all species are essentially a network of cellular and molecular mediators working together for the organism's survival.

Rodents and non-human primates are the most common animal-based models in endometriosis research with advantages and disadvantages. Rodents, such as rats, mice, and hamsters have been used to investigate basic mechanisms and the development of new drugs. They are easy to handle and relatively inexpensive animals to work with; however, endometriosis does not develop naturally in rodents, possibly because the endometrium is not shed during the estrous cycle. To work with this model, homologous or heterologous uterine tissue has to be surgically introduced in the peritoneal cavity of these animals [31].

Conversely, endometriosis develops spontaneously in non-human primate models that have a natural menstrual cycle, such as rhesus monkeys and baboons [32]. Similarly to women, the duration of the menstrual cycle in female Rhesus (Macaca mulatta), cynomolgus (Macaca fascicularis) and pigtailed macaques (Macaca nemestrina)) is around 28 days [33]. These animals also have retrograde menstruation and their reproductive anatomy (uterus, fallopian tubes and ovaries morphology) and endocrine influences are similar to humans [34]. Although non-human primates would be interesting models to study endometriosis, they are captivitysensitive animals and costly to maintain. In addition, spontaneous endometriosis develops at considerable low frequencies, which limits primates' use for research purposes. Moreover, public opposition to non-human primate research has been rising [35] and stricter recommendations exist for future work with non-human primates are being designed. The latest report from the Scientific Committee on Health Environmental and Emerging Risks (SCHEER) on the need for non-human primates in biomedical research, production and testing of products and devices, updated in 2017, proposes 23 recommendations for future work with non-human primates.

Some of those recommendations are requirements already listed in the Europe Union Directive 2010/63, and have been merged into the committees' series of recommendations in order to amplify their importance and to encourage full and rapid implementation, such as: to check, case by case, the need of using non-human primates; to provide solid harm-benefit assessment of using non-human primates; and to identify circumstances in which to avoid using non-human primates [36].

Other less representative models used in endometriosis studies are chicken, rabbit, sheep and cow [37]. The studies using these models frequently focus on a particular physiopathological aspect, which can be emulated. 
Chickens have been used for disease mechanism studies, as for instance, a chicken embryo chorioallantoic membrane model was used to show the invasiveness potential of epithelial and stromal endometriosis cells [40] and the role of angiogenesis in lesions formation [38]. In turn, rabbits and cows have been used to model key points of endometriosis-associated infertility. The understanding of reduced fertility with the increase of prostaglandins was observed first in studies using rabbits [41]. In vitro oocyte maturation studies, using bovine oocytes and follicular fluid collected from women with endometriosis, showed damage to the meiotic spindle, probably caused by elevated oxidative stress [39, 42].

Even though some contribution to advancing the knowledge of endometriosis physiopathology originated from animal research, none of the reported animal models has yet led to successful novel therapies [43, 44]. In contrast, patient tissue or fluid-derived in vitro models as well as other human-based models, such as patient tissue and observation studies, have given substantial knowledge to the development of possible therapy targets, which could be tested in human-based clinical trials. In vitro models present several advantages over animal models, namely the easy access to target cells enabling identification of critical cellular and molecular contributors to the disease. Although not contemplating the complete biological system, in vitro models enable highthroughput screening for therapeutic compounds, with overall lower ethical issues and costs. Important findings on the physiopathology of endometriosis have come from classic in vitro cultures of endometriosis-derived stromal [45] or epithelial cells [46]; more recently three-dimensional (3D) cultures [47] also came into use with several advantages.

\section{Animal models \\ Contribution of studies with non-human primates to endometriosis research}

Much of the knowledge of pathophysiological processes such as tissue attachment [18], endometriosis-related pain mediators [12], hormonal dependency, progesterone resistance, angiogenesis, oxidative stress and inflammation has evolved from research on non-human primate models done in the past [48] and also from non-animal research [25]. The main reason for conducting research on human disease mechanisms in animal models is the simulation of the disease and, eventually, the translation of findings to humans. Although most of animal model studies in general, including non-human primate models, have been used to understand the mechanism of action of approved drugs on endometriotic lesions and on the treatment of other symptoms, they have also failed to provide convincing translatable results related to the disease mechanisms, toxicity of compounds, teratogenic effects, correct dosage and drugs delivery routes [49]. Many studies using non-human primates were repeated many times to the point that ethical reasons emerged to restrict the number of animals in investigation.

An experiment in baboons with endometriosis, revealed that, by reducing the expression of aromatasemRNA with Letrozole, an aromatase inhibitor, size and volume of peritoneal lesions were diminished [50], suggesting a correlation between estrogen restriction and endometriosis lesion shrinking. In addition, progesterone antagonists (RU-486-mifepristone and ZK 98.299onapristone) that block estrogen effects on endometrium and cause endometrial atrophy by suppressing proliferation were shown to be effective at both the reduction of the lesions and control of clinical symptoms. These studies initially conducted in non-human primate models reaffirmed the use of labeled drugs on endometriosis treatment by demonstrating how those therapies could be effective at controlling clinical symptoms [51]. However, none of the recent studies carried on these primates to test new drugs for endometriosis was found in the biomedical literature, possibly due to the prevalent culture of avoiding publication of negative results $[52,53]$. Therefore, there is the possibility that non-human primate models are failing to reveal novel treatment strategies, since there has not been real progress in drug (label or off-label) management of endometriosis. The available treatments and/or surgery are often insufficient to eliminate the disease and to prevent its recurrence.

\section{Contribution of rodent models to endometriosis research}

Because rodent models can be used for disease studies and can be genetically modified, they have been used to investigate endometriosis pathophysiology by means of several molecular techniques. The studies were focused mainly on finding possible new therapeutic targets and/ or on improving existing ones [54], even though extrapolating data between species is difficult.

Isogenic mouse strains allowed mechanistic and regulatory approaches to investigation without the interference of the individual genetic variation existing in humans. These models offered insights into the effects of ectopic endometrial tissue growth [55], in vitro fertilization, embryo development and implantation, and oviduct transport [56]. Pain mechanisms [57], as well as inflammation [58] and organ adhesion [59] were also studied in mice. However, one of the major problems of using rodents in endometriosis research is that only superficial lesions can be induced in these animals and those are the simplest and perhaps the least clinically important types of lesion. No study to date has been able to model deep endometriotic lesions and 
perhaps this is one of the reasons for the lack of success of rodent models to generate applicable results to human endometriosis in the areas of pathophysiology and therapeutics.

Even though rodent models have provided information to endometriosis on inflammation [54], oxidative stress [60] and animal reproduction [61] there are still gaps in knowledge. Immune modulators [62] and antioxidant/oxidative stress compounds have also been studied in rodent models, but attempts to translate the results to humans did not lead to affective endometriosis therapies. It became clear that a number of women treated in clinical trials with hormonal therapies translated from results obtained in animal models of the disease did not respond to these treatments [63] needing surgical lesion excision to alleviate symptoms. It is important to mention that the current available hormonal therapies are not indicated for women trying to become pregnant because they interfere with ovulation. Because alternative therapies such as immune modulators have been shown to reduce lesion size in rodents [64] there was hope that they would also be effective in women and might improve fertility. However, this hypothesis was not confirmed in women with endometriosis.

The rodent model requires the surgical induction of endometriosis, usually done by transplanting endometrial tissue or cells into the animal's abdominal cavity. This procedure leads to superficial endometriotic lesions, a model that basically favors the study of inflammatory processes caused by the implanted lesions instead of those caused by endometriosis itself. Recurrent studies in rodent models indicating putative therapeutic molecules, which eventually fail to be active in humans, are common in research on endometriosis, but also on other human diseases. One particular example is the treatment with resveratrol. In the mouse endometriosis-induced model this natural phenol showed promising results by reducing lesion size, inhibiting angiogenesis and inflammation in several overlapping studies [65-67]; however, when tested in affected women in a trial (ClinicalTrials.gov Identifier: NCT02475564) the results were disappointing.

Recently, a mouse model that mimics endometrial shedding similar to human menstruation was created. It is claimed to provide a closer model to human reproductive physiology. That model still requires more indepth validation as it still presents limitations such as variation in the endometrial response, and in the duration and quantity of the hormonal stimulus $[54,68]$.

\section{Contribution of animal models to a breakthrough in endometriosis treatments: from disease experimental models to clinical trials}

While there is exponential growth in the number of preclinical endometriosis studies, the translation of findings obtained by studies on animal models into clinical trials has been poor. A recent search in PubMed using a simple searching strategy "endometriosis and experimental model" retrieved 1230 published articles in February of 2019 compared to 469 in 2009, which amounts to a $150 \%$ increase. In fact, no novel therapeutic compounds for endometriosis have been proposed and there is only a small number of published clinical studies on drug development for endometriosis. This is an indication that the understanding of the disease and of its processes is still scarce [52,69]. A fact that also reveals the failure of several attempts to translate experimental investigation results to the clinical sphere is evidenced by the number of collapsed phase II or III trials [28]. Again, most studies producing negative results and/or with conflict of interest are not published [52], a situation that leads to analytical bias and affects the perception of the existing state of research on endometriosis.

The high rate of potential drug therapies that fail at efficacy testing protocols in humans (Table 1) is noteworthy. Even when previous animal studies had shown that a treatment would be effective and safe, the subsequent failure rate in humans was higher than $80 \%$. This situation suggests that preclinical animal studies are either not translatable at all or are not being accurately designed; therefore, studies of this type may be considered poor predictors of therapeutic efficacy of novel drugs in patients [70]. Although similar failure percentages are reported in drug discovery studies for other diseases, it brings into debate, in the case of endometriosis, the lack of reproducibility and translatability of animal studies to humans. The results stemming from animal research in the field of drug development would be a contributing factor to that observed failure when tested in human trials, raising the question of the quality of the results [71, 72].

We propose a thought-provoking illustration of that scenario in Table 2. We surveyed PubMed without determining dates for published articles on endometriosis that used animals as experimental models for testing antiinflammatory drugs. With the intent of comparing the outcomes of animal studies, a search on clinicaltrials.gov was performed for registered clinical trials of the same drugs used as human medication. Clearly, the number of ongoing or complete clinical trials testing drugs previously evaluated in animal models for the same disease is small. Out of 36 drugs which had been tested in animal studies of endometriosis, 32 were object of clinical 


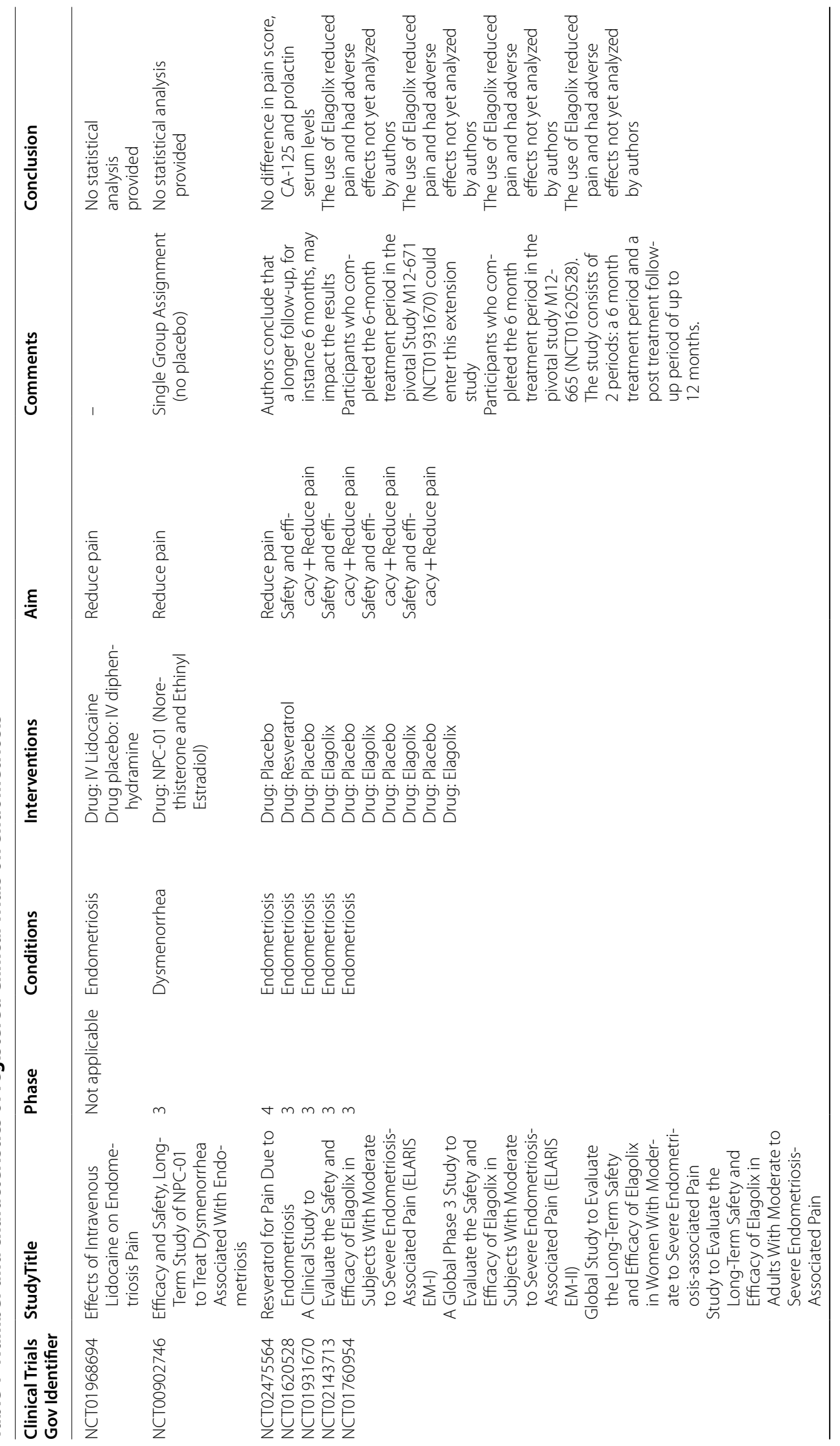


Malvezzi et al. J Transl Med ～～(2020) 18:311

Page 7 of 21

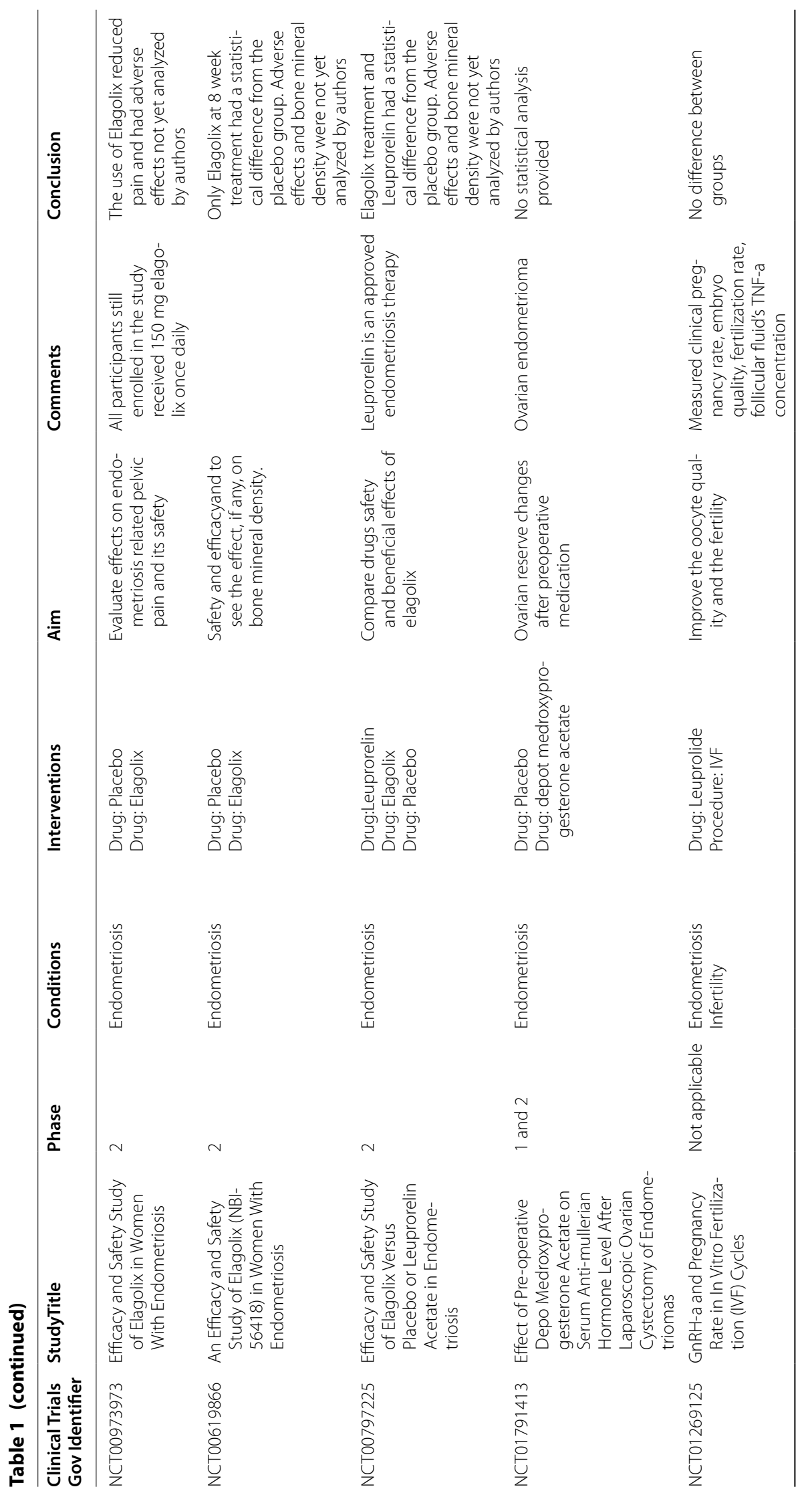




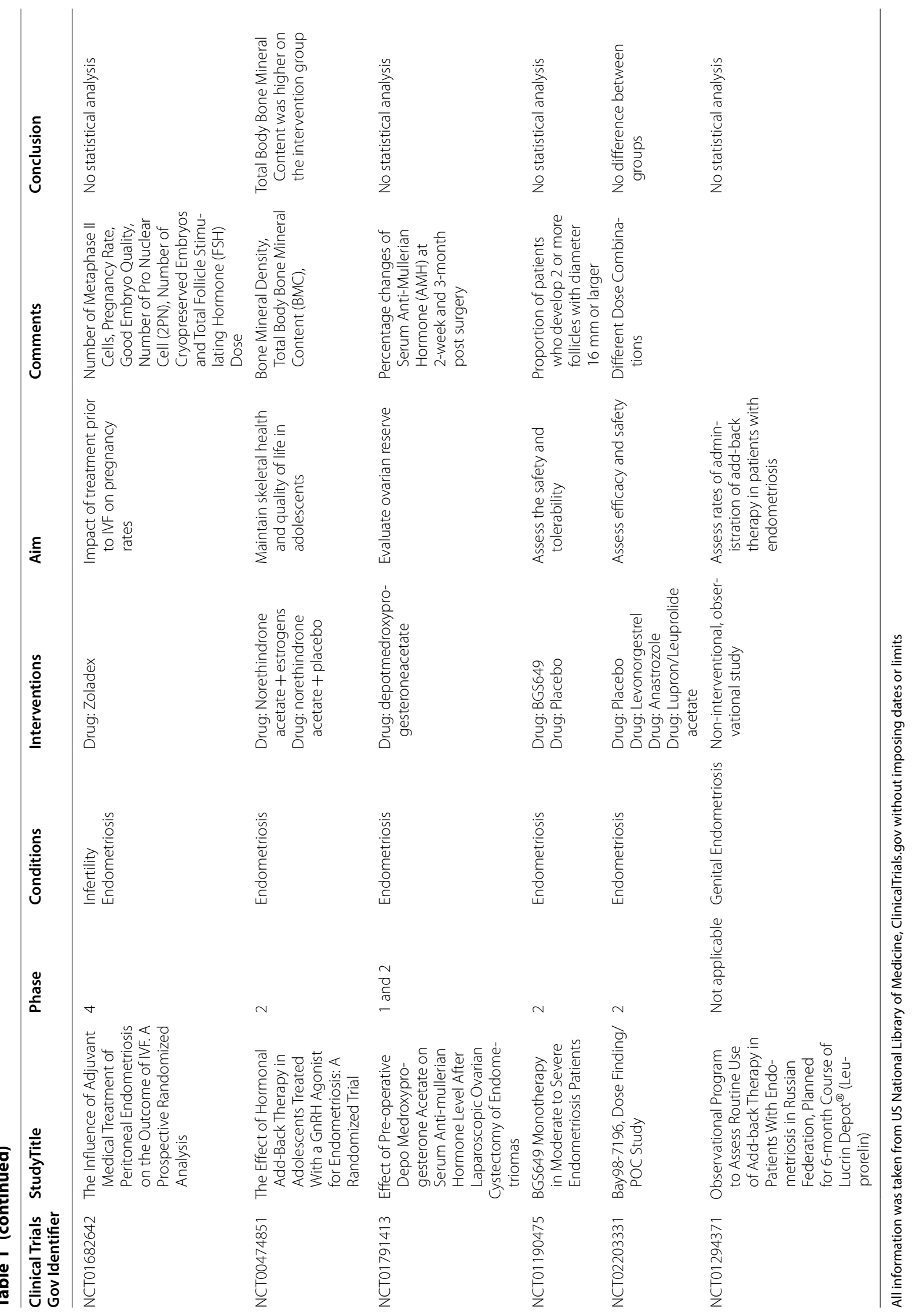




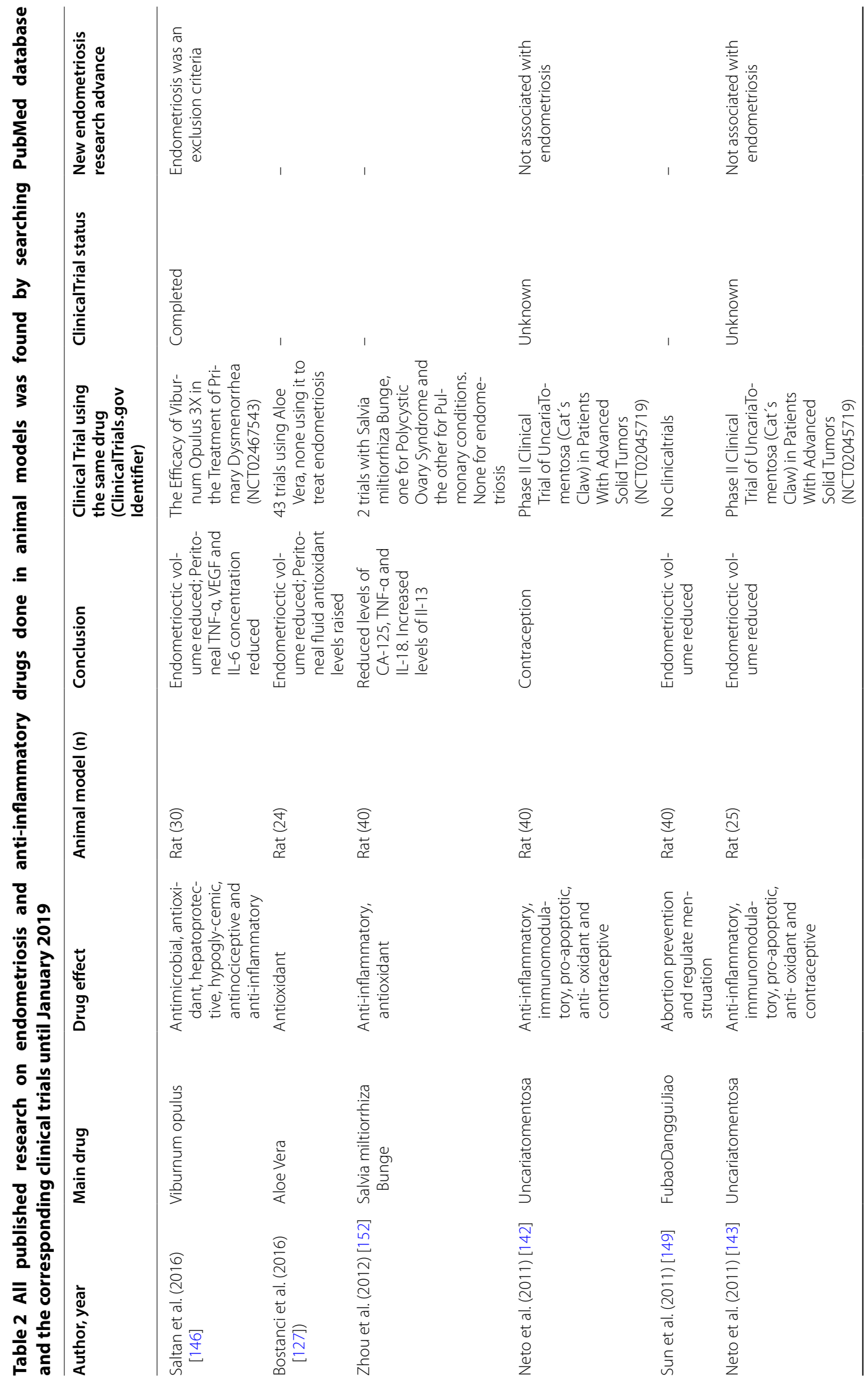




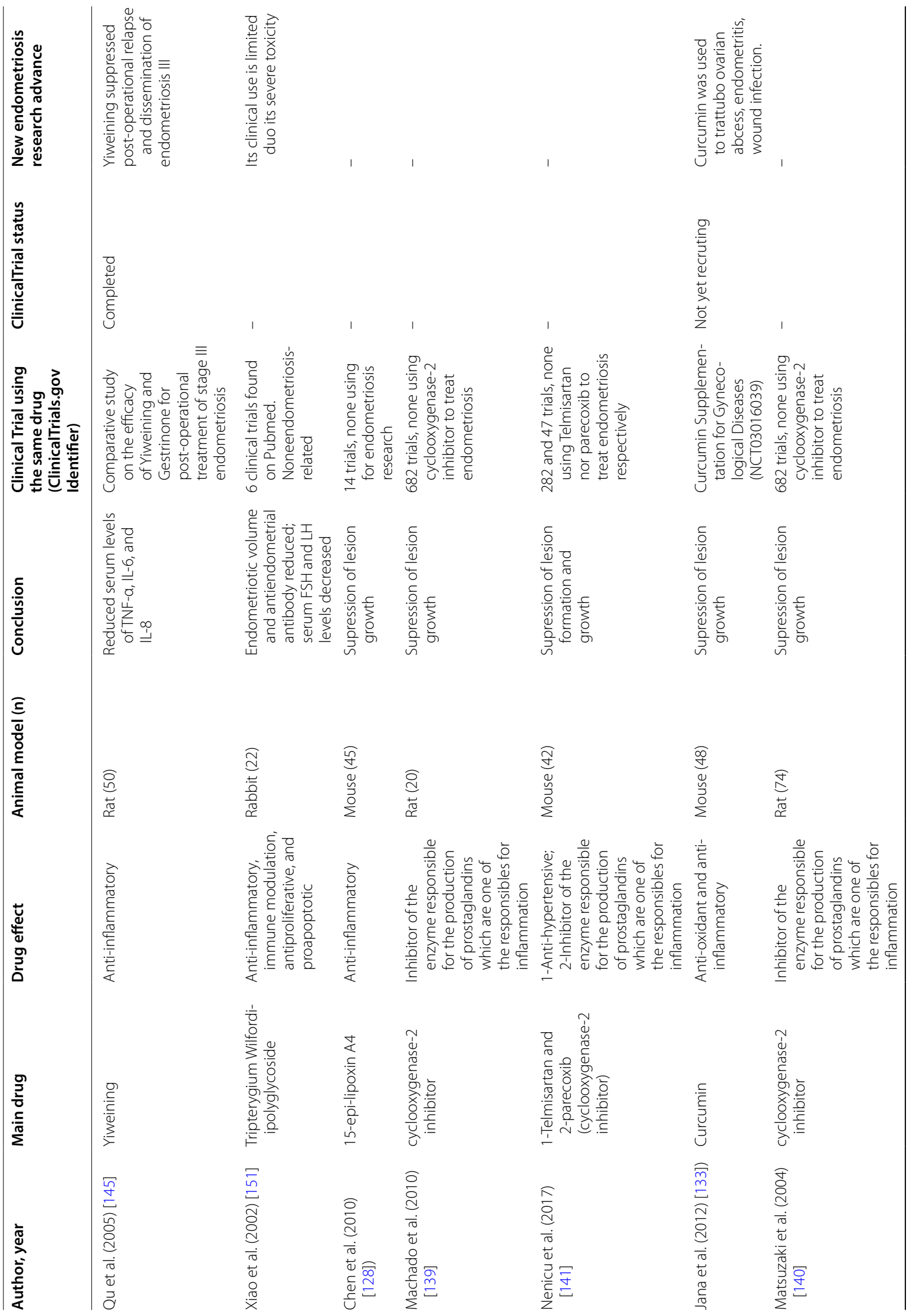




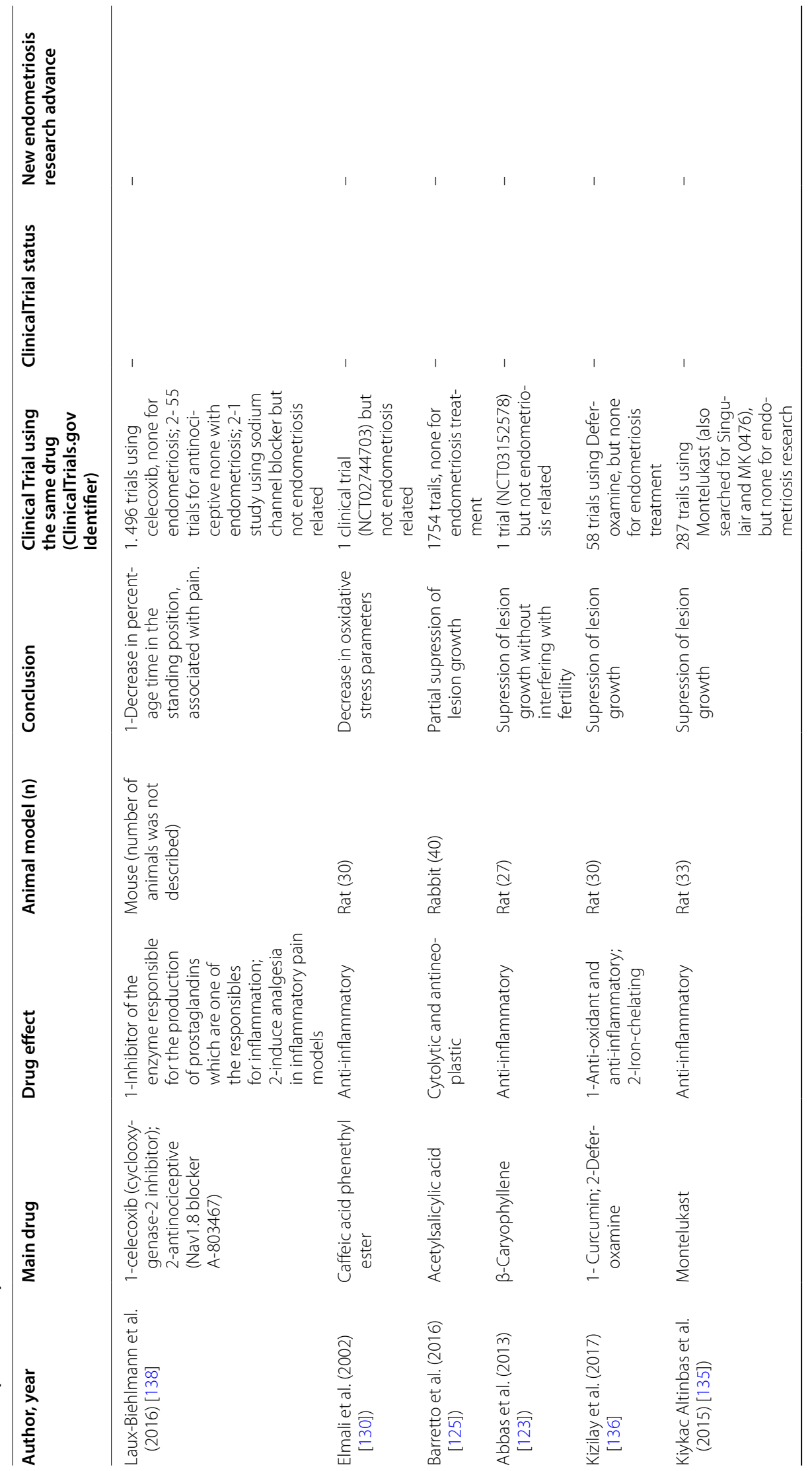



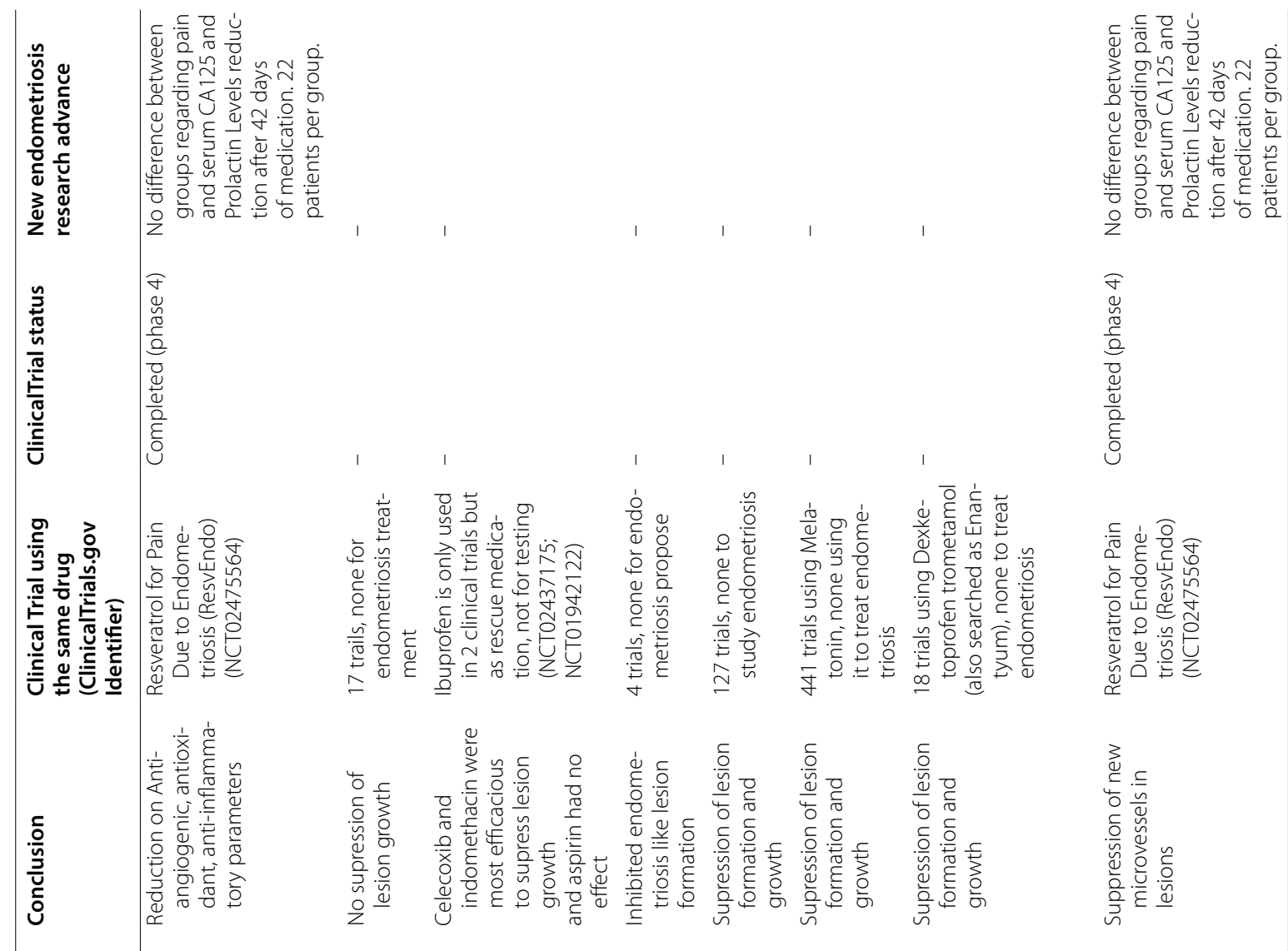

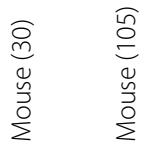

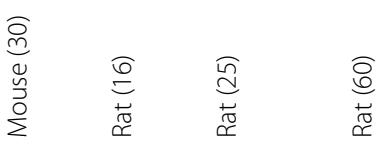
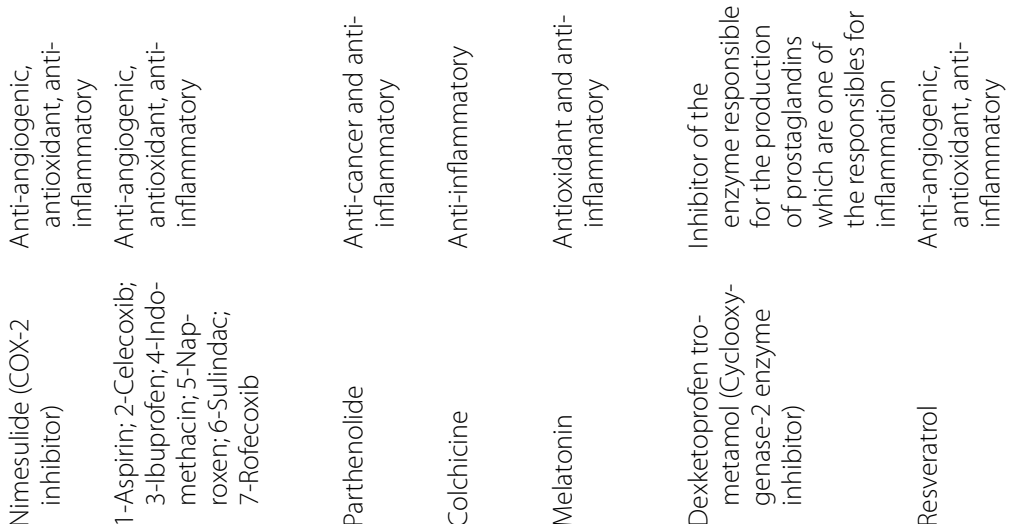

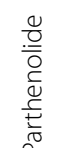
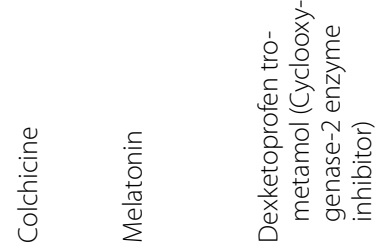

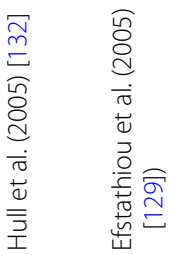

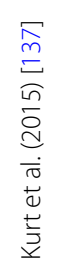

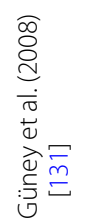

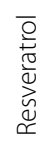

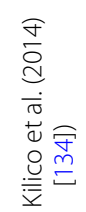

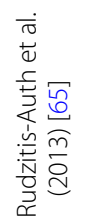




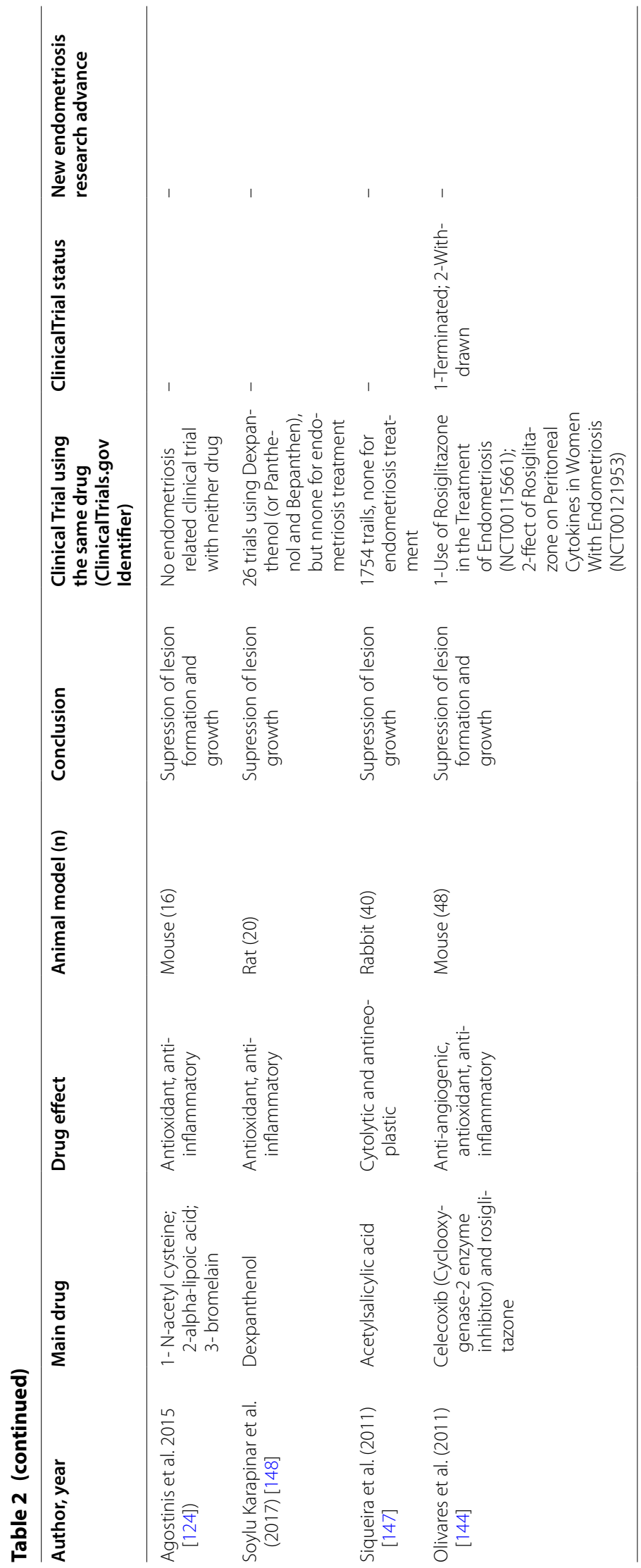


trials not related to endometriosis, while only 4 were (or are being) tested in clinical trials as treatments for endometriosis, namely: Resveratrol (NCT02475564), Yiweining [73], Curcumin (NCT03016039) and Rosiglitazone (NCT00115661; NCT00121953). Two of these four trials are finished by now, one is not yet recruiting, and one was interrupted (Table 2).

That small number of clinical trials shows that previous animal testing for endometriosis-active drugs does not translate in clinical trials to verify their effects on patients. We searched the United States of America National Library of Medicine-clinicaltrial.org website and found 213 registered clinical trials relating to endometriosis drug testing (last search was performed January 2019), 105 were "Completed", 36 were "Recruiting" or "Enrolling by invitation", 28 were "Not yet recruiting", "Active", or with "Not recruiting status", 20 were "Suspended", "Terminated" or "Withdrawn" and 24 had "Unknown status".

For all completed trials, only 19 were published and, of these, 18 aimed at finding novel therapeutic activities for specific endometriosis symptoms. All the investigated drugs had already been tested for other diseases and were approved by the FDA. Some of the tested drugs were specifically "labeled", while others were "off-label" drugs used for endometriosis treatment (Table 1) [51]. Out of those 18 studies, seven aimed at pain reduction, four were focused on fertility improvement, one study aimed at improving life quality of adolescents and nine studies aimed at improving drug tolerance and safety (some trials had multiples aims). Interestingly, none of these drugs undergoing new therapeutic testing originated from preclinical studies using animal models.

Another important point that reveals the lack of comparability between clinical trials and animal studies is the fact that, while animal-based studies on experimental drugs have lesion reduction as measured positive outcome of the test, most clinical trials have as main outcome the reduction of disease symptoms (mainly pain and infertility, or fertility preservation).

Moreover, the endpoint of most animal model studies is based on lesion regression, as if it would be considered an important endpoint in endometriosis research. However, endometriosis clinical trials (Table 1), do not concern and do not look for lesion regression when studying a potential new drug. Curiously, lesion regression has never been chosen as an end-point of clinical studies. Clinical studies were aimed at finding ways to mitigate symptoms, which seems to be the utmost point to be addressed for endometriosis [8, 74, 75]. An International Consensus Workshop proposed a list of priorities for endometriosis research and under the "treatment and outcome" section, lesion regression was not mentioned at all, as opposed to diminishing symptoms [76]. According to Paolo Vercellini's view, the treatment should not target the lesions but the clinical signs, as researchers should aim at providing patients comfort and address their main complaints [74] instead of masking advances with endpoints of questionable use for the progression of new drugs discovery. Thus, it is still debatable what would be the most adequate approach to study endometriosis. If endometriosis is seen as a chronic, yet incurable, but not a life-threatening disease, then mitigation or the end of symptoms seem to be reasonable approaches to improve quality of life for the patients. At least, this would be a goal until the etiology of endometriosis becomes clear and, in consequence, research will seek novel approaches.

\section{In vitro studies using patient-derived tissue and fluids, and in vivo human-based-models}

Although experimental research on animals whose goal was lesion regression failed to produce translatable data to humans, human-based research approaches to endometriosis (including clinical trials, observation and association studies) are generating the most relevant publications in this field. Notably, the most cited original and currently used article for understanding and classifying endometriosis grades is the Revised American Society for Reproductive Medicine classification of endometriosis: 1996. This article reports clinicians' observations of disease behavior by visual and histopathological analysis of biopsies [77]. In addition, when revising high-impact of endometriosis-narrative reviews [78], the bibliography cited by the reviewers focused mostly on in vitro patientderived tissue and/or fluids and on human-based studies, the ones that were considered to advance our knowledge of endometriosis. It is worth noticing that among most highly cited papers on endometriosis, there are two human-based studies. One of these deals with the deleterious effect of continuous ovulatory cycles on endometriosis persistence [79] and the other revealed a mutation in the ARID1Ain gene found in endometriosis-associated ovarian carcinomas [80]. Furthermore, a highly innovative target for the non-hormonal treatment of endometriosis, P2X3, which is thought to be associated with development and maintenance of chronic pelvic pain, was also identified without using animal models [81].

Highlights of advances brought about from humanbased research approaches comprise: large-scale integrated genome-wide RNA sequencing [82]; endometriosis peritoneal fluid a potent oxidative fluid and modifier of miRNA expression profile in eutopic cells [83]; miRNA analysis associated with pelvic pain [84]; modulation of pain [85], anxiety and depression [86]; tissue-specific expression analysis of endometriosis tissue samples by laser capture microdissection (reviewed 
in [87]); genetic associations between endometriosis and obesity-related traits [88].

Genomic wide association studies (GWAS) have emerged more than a decade ago [89] as an important tool to study complex genetic diseases. Particularly for endometriosis, GWAS has helped to infer causality and uncover pathogenic mechanisms. It may be helpful in order to dissect all possible phenotypes of the disease, although this has not been broadly tested yet. To date, GWAS revealed more than 10 genomic regions associated with endometriosis, a condition that explains less than $<4 \%$ of inheritance $[82,90]$. Some of these studies revealed, for instance, novel associations between endometriosis (and some specific phenotypes) with the Wnt Family Member 4 (WNT4) locus [91] and the mitogenactivated protein kinase (MAPK)-related pathway [90]. The gathered information has allowed new insights into the biological pathways that could be associated with the pathology of endometriosis, besides being indicative of new potential therapeutic targets.

\section{Contributions of in vitro models for endometriosis research}

Biopsies are important cell sources for in vitro culture. In endometriosis research cells cultured on flat surfaces, also called two-dimensional (2D) cellular models, have generated hundreds of publications. Co-culture models are cell cultures in which two (or more) different cell types are cultured together, often separated by a fluidpermeable membrane. They are mostly used to assess the effect of one cell type on another cell and also to verify how cells interact [92]. These two previous models lack important features for cellular function feature such as a cellular physicochemical microenvironment, tissuespecific architecture, and blood flow perfusion. In the quest to create better models to observe cell to cell interaction, investigators have recently started to use threedimensional (3D) models (sometimes called spheroid or organoid cultures) [93]. These 3D models aim at providing better phenotype and gene expression than $2 \mathrm{D}$ culture systems, opening the possibility to test interactions among different cells found in endometriotic lesions [94].

By means of in vitro conducted experiments, researchers have found elevated levels of cytokine and inflammatory mediators in the peritoneal cavity and phenotypic progesterone resistance, a condition seen in endometriosis patients [95]. Progesterone has anti-inflammatory activity and the results show a link between progesterone-resistance and chronic inflammatory states. Signaling by progesterone in endometrial cells induces suppression of NF-kB, which stands for nuclear factor kappa-light-chain-enhancer of the family of B proteins [96]. This suppression may lead to the establishment and maintenance of endometriosis implants because NF- $к B$ has the ability to regulate a large array of genes involved in different processes of immune and inflammatory responses, thus controlling genes related to cell proliferation, adhesion, apoptosis, and inflammation [97].

These findings have emerged from in vitro observations and originated a whole new group of drugs for endometriosis treatment. One example are the progestins, a class of drugs that inhibit inflammatory pathways, angiogenesis and oxidative stress in endometriotic cells. These and other observations have opened up a new field, which may be critical for understanding mechanisms underlying the development, progression, variability and symptomatology of endometriosis.

In addition, a study with $2 \mathrm{D}$ cell cultures found that inhibition of IL-1 $\beta$ in eutopic endometrial stromal cell cultures could potently alter decidualization in vitro, suggesting a way to improve endometrial receptivity and pregnancy success in women with endometriosis [98]. Moreover, with the use of 2D culture of eutopic endometrial stromal cells, researchers found increased expression of a gene ( $\mathrm{H} 19$ gene) in endometriosis. This gene is responsible for tumor cell invasion and migration, and is regulated by estrogen and progesterone. The dysfunction of such a gene might act as an important factor for endometrial stromal cell invasion and migration, contributing to fibrous tissue formation [99].

Basic research studies using cell cultures from endometriosis patients shed light on cellular behavior and possibly new ways of managing cellular growth. Dienogest was shown to downregulate the expression of CYP19A1 (aromatase gene), inflammatory and neuroangiogenesis in immortalized endometriotic epithelial cell lines [100], also in a spheroid cell culture system (3D system), dienogest inhibited mRNA prostagladin synthases, protein expression, and the nuclear factor- $\mathrm{k} B$ activation, which could contribute to therapeutic effect on endometriosis [101]. Recently, a double-blind phase 3 clinical trial showed the benefits of using dienogest for endometriosis treatment, by reducing endometriosis-associated pelvic pain [102], which could be also related to inhibition of prostaglandin mRNA synthases.

\section{Roadmaps for endometriosis research: perspectives on new approaches of endometriosis}

The ultimate desirable goal of modeling endometriosis is to be able to develop a strong project, hypothesis-driven, and based on solid science. We envision that with the advance of high throughput genomics analysis, epigenomics, transcriptomics, proteomics and metabolomics in cell biology, these analyses will be carried out in endometriosis-derived tissue samples. There will be a need for an integrated guideline of all "omics" to facilitate the 
access to research data and to validate and increase their reproducibility and robustness rates. This should also facilitate both interpretation and functional use of such data [103]. Importantly, it is expected that these data will provide alternative strategies for diagnosis and target the treatment of symptoms. The high-dimensional gene expression data presented by Linda Giudice's group [104] represent the first steps toward that approach, by putting forward a molecular classification of endometrium candidate-genes and offering a correlation with disease conditions and stage.

Besides inherent technical limitations such as difficulties to reach statistical power because of the large number of observations required, GWAS has recently allowed new insights into novel endometriosis-associated biological and pathogenetic pathways and giving rise to new hypotheses to understand that disease. For instance, a GWAS study suggested that the pathogenesis of advanced endometriosis is likely to be distinct from less severe disease [82]. This hypothesis is possible due to the integration of molecular sequencing/expression results with detailed clinical and demographic data. In fact, GWAS seems to have the potential to cover the complete spectrum of disease-related effects [82]. In endometriosis, no publication has yet explored the so-called phenomics (the set of phenotypes physical and biochemical traits by the organism due to genetic and environmental influences) approach, although this is a promising avenue [82]. Moreover, PhenoWAS, (Phenomics Wide Association Analysis) is an opposite way of looking at data in comparison to GWAS classical approach, and might serve as a powerful way to investigate endometriosis. PhenoWAS consists of investigating which diseases (many diseases at the same time) are associated with a given genetic variant [105]. This approach is only possible if a high-dimensional phenotypic dataset is available or very large and well phenotypically-characterized cohort is used.

Years ago, it would have been impossible to foresee the emergence of artificial intelligence (AI) models to advance our knowledge on disease. However, text analytics (text mining based on AI), high-throughput cellbased assays, automated microscopy-based high-content screening and convolutional neural network can facilitate the way we look at data. Text mining is a process of adapting a massive amount of unstructured information into significant interpretable data for research analysis, such as proteins, genes and other markers to eventually reach a set of findings relevant to endometriosis research [106]. AI can be applied to high-throughput cell-based assays' data and to automated microscopy-based highcontent screenings. Both approaches allow the parallel monitoring of multiple cell phenotypes, as well as the examination of cell shape changes under different conditions and the staining for surface and cytoplasmic molecules by fluorescence-labeled antibodies.

In endometriosis, $\mathrm{AI}$ and text mining were put to prove by unraveling endometriosis most important associated genes that were already published, besides discovering new ones, building a genome wide gene network [107]. This network, coupled with other AI applications, formed a list of 5 top genes to be studied in endometriosis and perhaps used as biomarkers for the disease. Another work implemented machine learning AI to find a relationship between endometriosis and other diseases, as for instance benign breast disease, cystitis and nontoxic goiter. Using a similarity matrix, the method evidenced other diseases that women with endometriosis had in common [108], showing that this would be a useful method for understanding how endometriosis works and how it could be associated with other disease and symptoms.

These techniques facilitate phenotype measurements of individual cells and analyses of heterogeneous responses, providing in-depth insights into biological processes [109]. Convolutional neural network (CNN), multi-scale convolutional neural network (MSCNN) and deep convolutional neural network (DCNN) are remarkable recent AI advances. Developing rapidly over the past 6 years, those approaches are capable of fast "learning" from captured images (by sensing pixel intensity values) or from input data. By teaching itself, these programs can automatically improve their analysis (machine learning) $[110,111]$. In order to become the next-generation tool for the diagnosis of human disease, $\mathrm{CNN}$ in all its different forms, MSCNN and DCNN, are being tested and compared to diagnosis by clinicians, proving to be more accurate, sensitive and specific ways for the classification of some diseases such as lung cancer [112]. A potential contribution of such a system to clinical decision making and therapeutic management of endometriosis should help with earlier diagnosis. This may contribute to identify disease phenotypes and how they relate to clinical symptoms, thus offering the possibility of custom-tailored treatments according to phenotypes (based on symptoms, images or gene expression features) and genotypes (based on DNA sequencing). In addition, AI combined with bioinformatics can be useful for retrieving relevant data on novel targets or markers for endometriosis [113], as well as improving diagnosis, the understanding of gene pathways and protein networks.

Cell-culture has helped our understanding of gene and protein expression [114], the roles of hormones in endometriosis [115] and also the possibility to recreate early stages of endometriosis in a "Petri-dish" [116]. Three-dimensional models offer the opportunity to study 
aspects of endometrial stromal and epithelial cells communication and paracrine cross-talk between stromal and epithelial cells [117]. While endometrial and endometriotic cells can also be cultivated with biopolymer and pre-fabricated scaffolds, hydrogels and cell sheets, microfluidic devices like "organ-on-chips" are gaining space as new research models for endometriosis [118]. Organ-on-chips allows morphological and functional changes of cells to occur in a microfluidic device, with the aim of reproducing enough cellular functions that the model can be used to test therapeutic drugs and toxicity effects [119]. By creating an "endometrium-onchip" to study the role of the perivascular stroma in the human endometrium, this method could indirectly offer information on in vivo mechanisms [120]. Moreover, the breakthrough of cultivating the reproductive tract "ona-chip" [121] has offered hope to model cyclic hormonal effects in hormone-dependent diseases, such as endometriosis. Thus, endometriosis research can now count on several new approaches to improve our knowledge that is, yet, rather limited.

The lack of translation of results from animal to human has been highly disappointing. Situations like this have led many researchers to consider the use of animals to model human disease is a limited path concerning time, resources, and money. Perhaps a positive outcome of the failure in translating research focused on therapy from animal experiments to human trials is the recognition of the limitations of using animals for experimental purposes [35].

\section{Final remarks}

While researchers working with rodent and other animal models of endometriosis investigate reduction of lesion size and of cell proliferation, apoptosis parameters, or protein and gene expression data, from the point of view of achieving or advancing therapy for human endometriosis these models have provided scanty results. Analysis of available reported publications shows that animal models hardly produce robust data to provide candidate drugs for clinical trials. Thus, it is questionable whether these models should constitute the main strategy for understanding endometriosis pathophysiology and for the development of new therapies.

Hardly new compounds will emerge for the treatment of endometriosis based on therapeutic interventions in animal models. It is important to note that although the use of animals presents handling and physiological disadvantages, regulatory agencies (i.e., FDA United States and ANVISA Brazil) still require small and large animals for new drug testing, particularly for efficacy, toxicology and safety analysis. A topic of discussion by the scientific community, industries and regulatory agencies are alternatives to in vivo testing of efficacy, toxicology and safety of new drugs, and the real value of in vivo tests. In vitro and in silico tests have been established and are under validation, particularly for efficacy studies, instead of using naturally or induced animal models. Advances in in vitro modeling technologies, as for instance 3D blood vessels printing [122], are promising new platforms for the understanding of angiogenesis and vasculogenesis physiology.

\section{Conclusion}

Finally, we envision personalized treatments that would utilize complex decision algorithms (text mining, neural networks, etc.) capable of integrating genomics, transcriptomics, epigenomics, proteomics, microbiome, exposures, behaviors, informatics and clinical/phonotypical data both cross-sectionally and throughout the patients' lifetime. In our view, health regulatory agencies should question the currently required preclinical data from non-translatable animal models, and instead more multicenter, randomized controlled trials should be performed to test different endometriosis treatment options against defined outcome measures, such as relief of pain and/or infertility. This will bring back quality of life to endometriosis-suffering women.

\section{Abbreviations \\ CNN: Convolutional neural network; DCNN: Deep convolutional neural net- work; GWAS: Genomic wide association studies; MSCNN: Multi-scale convolu- tional neural network; SCHEER: Scientific Committee on Health Environmental and Emerging Risks; 3D: Three-dimensional.}

\section{Acknowledgments}

We would like to thank Dra. Ises de Almeida Abrahamsohn for English revision and for critically reading the manuscript. We would like to acknowledge Isis Mozetic for technical support on drawing the figures. We would like to thank Marcia Triunfol, Lindsay Marshall and Brinda Poojary for their comments and suggestions to the manuscript.

\section{Authors' contributions}

HM made substantial contributions to the conception, design of the work; acquisition, analysis, interpretation of data; drafted the work and revised it. HM also approves the submitted version and is accountable for her own contributions and had ensure that questions related to the accuracy or integrity of any part of the work are appropriately investigated, resolved, and documented in the literature. EBM substantially revised the work and approves the submitted version and is accountable for her own contributions and had ensure that questions related to the accuracy or integrity of any part of the work are appropriately investigated, resolved, and documented in the literature. SP have made substantially contribution to the design of the work and substantively revised it. SP approves the submitted version and is accountable for his own contributions and had ensure that questions related to the accuracy or integrity of any part of the work are appropriately investigated, resolved, and documented in the literature. CAP made substantial contributions to the conception, design of the work, interpretation of data and revised it. CAP also approves the submitted version and is accountable for her own contributions and had ensure that questions related to the accuracy or integrity of any part of the work are appropriately investigated, resolved, and documented in the literature. All authors read and approved the final manuscript. 


\section{Funding}

This work was supported by the Humane Society International. HM is supported by São Paulo Research Foundation (FAPESP-Fundação de 464 Amparo à Pesquisa do Estado de São Paulo; Grant Number 2018/11042-0). CAP has a visiting Scientist institutional Grant from Sociedade Beneficiente Israelita Brasileira Albert Einstein (UNIEMP).

\section{Availability of data and materials}

All data generated or analysed during this study are included in this published article [and its supplementary information files].

\section{Ethics approval and consent to participate}

Not applicable.

\section{Consent for publication}

Not applicable.

\section{Competing interests}

The authors declare that they have no competing interests.

\section{Author details}

${ }^{1}$ Hospital Israelita Albert Einstein, São Paulo, SP 05652-900, Brazil. ${ }^{2}$ Instituto Butanta- EstabilidadeBiotech Quality Control, São Paulo, SP 05503-900, Brazil.

\section{Received: 1 May 2020 Accepted: 28 July 2020}

Published online: 12 August 2020

\section{References}

1. Fuldeore M, Yang H, Du EX, Soliman AM, Wu EQ, Winkel C. Healthcare utilization and costs in women diagnosed with endometriosis before and after diagnosis: a longitudinal analysis of claims databases. Fertil Steril. 2015;103(1):163-71.

2. De Graaff AA, Dirksen CD, Simoens S, De Bie B, Hummelshoj L, D'Hooghe TM, et al. Quality of life outcomes in women with endometriosis are highly influenced by recruitment strategies. Hum Reprod. 2015;30(6):1331-41.

3. Neal DM, McKenzie PJ. Putting the pieces together: endometriosis blogs, cognitive authority, and collaborative information behavior. J Med Libr Assoc [Internet]. 2011;99(2):127-34.

4. Bulletti C, Coccia ME, Battistoni S, Borini A. Endometriosis and infertility. J Assist Reprod Genet. 2010;27:441-7.

5. Morassutto C, Monasta L, Ricci G, Barbone F, Ronfani L. Incidence and estimated prevalence of endometriosis and adenomyosis in Northeast Italy: a data linkage study. PLoS ONE. 2016;11(4):1-11.

6. Eisenberg VH, Weil C, Chodick G, Shalev V. Epidemiology of endometriosis: a large population-based database study from a healthcare provider with 2 million members. BJOG An Int J Obstet Gynaecol. 2017; 125(1):55-62.

7. Schliep K, Chen Z, Stanford J, Xie Y, Mumford S, Hammoud A, et al Endometriosis diagnosis and staging byoperating surgeon and expert review usingmultiple diagnostic tools: an inter-rateragreement study. BJOG An Int J Obstet Gynaecol. 2017;124:220-9.

8. Kennedy S, Bergqvist A, Chapron C, D'Hooghe T, Dunselman G, Greb R, et al. ESHRE guideline for the diagnosis and treatment of endometriosis. Hum Reprod. 2005;20(10):2698-704.

9. Mahmood TA, Templeton AA, Thomson L, Fraser C. Menstrual symptoms in women with pelvic endometriosis. J Obstetr Gynaecol. 1991;98(June):558-63.

10. Balasch J, Fabregues F, Carmona F, Ordi J, Martinez-roman S, Vanrell JA. Visible and non-visible endometriosis at laparoscopy in fertile and infertile women and in patients with chronic pelvic pain: a prospective study. 1996;11(2):387-91.

11. Fauconnier A, Chapron C. Endometriosis and pelvic pain: epidemiological evidence of the relationship and implications. Hum Reprod Update. 2005;11(6):595-606.

12. Howard FM. Endometriosis and Mechanisms of Pelvic Pain. J Minim Invasive Gynecol. 2009;16(5):540-50. https://doi.org/10.1016/j. jmig.2009.06.017.
13. de Fonseca M, Aragao LC, Sessa FV, de Resende JA, Crispi CP, Crispi CP. Interrelationships among endometriosis-related pain symptoms and their effects on health-related quality of life: a sectional observational study. Obstet Gynecol Sci. 2018;61(5):605-14.

14. Farquhar C. Endometriosis. BMJ. 2007;334(7587):249-53.

15. Colette $\mathrm{S}$, Donnez J. Animal models in endometriosis experimental research| Modèles animaux dans la recherche expérimentale sur l'endométriose. Gynecol Obstet Fertil. 2012;40(9):494-6.

16. Sampson JA. Metastatic or embolic endometriosis, due to the menstrual dissemination of endometrial tissue into the venous circulation. Am J Philol. 1927;3:2.

17. Brueggmann D, Templeman C, Starzinski-Powitz A, Rao NP, Gayther SA, Lawrenson K. Novel three-dimensional in vitro models of ovarian endometriosis. J Ovarian Res. 2014;7:1.

18. Greaves E, Critchley HOD, Horne AW, Saunders PTK. Relevant human tissue resources and laboratory models for use in endometriosis research. Acta Obstet Gynecol Scand. 2017;96(6):644-58.

19. Bellelis P, Podgaec $S$, Abrão MS. Environmental factors and endometriosis. Rev Assoc Med Bras. 2011;57(4):448-52.

20. Kobayashi $\mathrm{H}$, Imanaka S, Nakamura $\mathrm{H}$, Tsuji A. Understanding the role of epigenomic, genomic and genetic alterations in the development of endometriosis (review). Mol Med Rep. 2014;9(5):1483-505.

21. Augoulea A, Alexandrou A, Creatsa M, Vrachnis N, Lambrinoudaki I. Pathogenesis of endometriosis: the role of genetics, inflammation and oxidative stress. Arch Gynecol Obstet. 2012;286(1):99-103.

22. Piccinato CA, Malvezzi H, Gibson DA, Saunders PTK. SULFATION PATHWAYS: contribution of intracrine oestrogens to the aetiology of endometriosis. J Mol Endocrinol. 2018;61(2):T253-70.

23. McKinnon B, Mueller M, Montgomery G. Progesterone Resistance in Endometriosis: an Acquired Property? Trends Endocrinol Metab. 2018:29(8):535-48.

24. Arruda MS, Petta CA, Abrão MS, Benetti-Pinto CL. Time elapsed from onset of symptoms to diagnosis of endometriosis in a cohort study of Brazilian women. Hum Reprod. 2003;18(4):756-9.

25. Barbieri RL. Reproductive history and endometriosis among premenopausal women. Obstet Gynecol. 2004;104(5):965-74.

26. Ahn SH, Monsanto SP, Miller C, Singh SS, Thomas R, Tayade C. Pathophysiology and immune dysfunction in endometriosis. Vol. 2015, BioMed Research International. 2015.

27. Hastings JM, Ph D, Fazleabas AT. Future Directions in Endometriosis Research EXPERIMENTAL MODELS OF. Semin Reprod Med. 2003;21:2.

28. Kimmelman J, Federico C. Consider drug efficacy before first-in-human trials. Nature. 2017;542(7639):25-7.

29. Grignolo A, Pretorius S. Phase III trial failures: costly, but preventable. Appl Clin Trials. 2016;25:8.

30. McGonigle P, Ruggeri B. Animal models of human disease: challenges in enabling translation. Biochem Pharmacol. 2014;87(1):162-71. https:// doi.org/10.1016/j.bcp.2013.08.006

31. Edwards AK, Nakamura DS, Virani S, Wessels JM, Tayade C. Animal models for anti-angiogenic therapy in endometriosis. J Reprod Immunol. 2013;97(1):85-94. https://doi.org/10.1016/j.jri.2012.10.012.

32. Merrill JA. Spontaneous endometriosis in the Kenya baboon (Papio doguera). Am J Obstet Gynecol. 1968;101(4):569-70. https://doi. org/10.1016/0002-9378(68)90572-3.

33. Brenner RM, Slayden OD. Molecular and functional aspects of menstruation in the macaque. 2012;309-18.

34. D'Hooghe TM, Bambra CS, Suleman MA, Dunselman GA, Evers HL, Koninckx PR. Development of a model of retrograde menstruation in baboons (Papio anubis)**Supported by the Commission of the European Communities (DG VIII Development and DG XII Science, Research and Development) and by the Vlaamse Interuniversitaire Raad. Flemish Int Fertil Steril. 1994;62(3):635-8.

35. Grimm DUS. labs using a record number of monkeys. Science. 2018:362(6415):630

36. Vermeire $T$, Epstein $M$, Badin RA, Flecknell PA, Hoet P, Hudson-Shore M, Jones D, Krätke R, Langermans J, Prescott MJ, Simonnard A TE. Final opinion on the need for non-human primates in biomedical research, production and testing of products and devices (update 2017). Sci Comm Heal Environ Emerg Risks. 2017.

37. Grümmer R. Animal models in endometriosis research. Hum Reprod Update. 2006;12(5):641-9. 
38. Nap AW, Dunselman GAJ, Griffioen AW, Mayo KH, Evers JLH, Groothuis PG. Angiostatic agents prevent the development of endometriosislike lesions in the chicken chorioallantoic membrane. Fertil Steril. 2005;83(3):2004-6.

39. Da Broi MG, Malvezzi H, Paz CCP, Ferriani RA, Navarro PAAS. Follicular fluid from infertile women with mild endometriosis may compromise the meiotic spindles of bovine metaphase II oocytes. Hum Reprod. 2014;29(2):315-23.

40. Maas JWM, Groothuis PG, Dunselman GAJ, De Goeij AFPM, StruijkerBoudier HAJ, Evers JLH. Development of endometriosis-like lesions after transplantation of human endometrial fragments onto the chick embryo chorioallantoic membrane. Hum Reprod. 2001;16(4):627-31.

41. Schenken RS, Asch RH. Surgical induction of endometriosis in the rabbit: effects on fertility and concentrations of peritoneal fluid prostaglandins. Fertil Steril. 1980;34(6):581-7. https://doi.org/10.1016/S0015 $-0282(16) 45199-X$

42. Malvezzi H, Da Broi MG, Meola J, Rosa-E-Silva JC, Ferriani RA, Navarro PA. Peritoneal fluid of women with endometriosis reduces SOD1 in bovine oocytes in vitro maturation. Cell Tissue Res. 2018;372(3):621-8.

43. Kyama CM, Mihalyi A, Chai D, Simsa P, Mwenda JM, D'Hooghe TM. Baboon model for the study of endometriosis. Women's Health. 2007:3(5):637-46. https://doi.org/10.2217/17455057.3.5.637.

44. Tirado-González I, Barrientos G, Tariverdian N, Arck PC, García MG, Klapp $\mathrm{BF}$, et al. Endometriosis research: animal models for the study of a complex disease. J Reprod Immunol. 2010;86(2):141-7.

45. Canosa S, Moggio A, Brossa A, Pittatore G, Marchino GL, Leoncini S, et al. Angiogenic properties of endometrial mesenchymal stromal cells in endothelial co-culture: an in vitro model of endometriosis. Mol Hum Reprod. 2017;23(3):187-98.

46. Lac V, Huntsman DG. Distinct developmental trajectories of endometriotic epithelium and stroma: implications for the origins of endometriosis. J Pathol. 2018;246(3):257-60.

47. Laschke MW, Menger MD. In vitro and in vivo approaches to study angiogenesis in the pathophysiology and therapy of endometriosis. Hum Reprod Update. 2007:13(4):331-42.

48. Fazleabas AT. Progesterone resistance in a baboon model of endometriosis. Semin Reprod Med. 2010;28(1):75-80.

49. Zurlo J. No animals harmed: toward a paradigm shift in toxicity testing. Spec Rep Anim Res Ethics Evol Views Pract. 2012;42(6):23-6.

50. Langoi D, Pavone ME, Gurates B, Chai D, Fazleabas A, Bulun SE. Aromatase inhibitor treatment limits progression of peritoneal endometriosis in baboons. Fertil Steril. 2013;99(3):656-62.

51. Quaas AM, Weedin EA, Hansen KR. On-label and off-label drug use in the treatment of endometriosis. Fertil Steril. 2015;103:3.

52. Guo S-W, Evers JLH. Lack of transparency in clinical trials. Obstet Gynecol. 2013;121:6.

53. Guo SW, Hummelshoj L, Olive DL, Bulun SE, D'Hooghe TM, Evers JLH. A call for more transparency of registered clinical trials on endometriosis. Hum Reprod. 2009;24(6):1247-54.

54. Greaves E, Cousins FL, Murray A, Esnal-Zufiaurre A, Fassbender A, Horne AW, et al. A novel mouse model of endometriosis mimics human phenotype and reveals insights into the inflammatory contribution of shed endometrium. Am J Pathol. 2014;184(7):1930-9.

55. Rakhila H, Girard K, Leboeuf M, Lemyre M, Akoum A. Macrophage migration inhibitory factor is involved in ectopic endometrial tissue growth and peritoneal-endometrial tissue interaction in vivo: a plausible link to endometriosis development. PLoS ONE. 2014;9:10.

56. Piromlertamorn W, Saeng-anan U, Vutyavanich T. Effects of ovarian endometriotic fluid exposure on fertilization rate of mouse oocytes and subsequent embryo development. Reprod Biol Endocrinol. 2013;11(1):1.

57. Alvarez $P$, Levine JD. Screening the role of pronociceptive molecules in a rodent model of endometriosis pain. J Pain. 2014;15(7):726-33.

58. Cenksoy PO, Oktem M, Erdem O, Karakaya C, Cenksoy C, Erdem A, et al. A potential novel treatment strategy: inhibition of angiogenesis and inflammation by resveratrol for regression of endometriosis in an experimental rat model. Gynecol Endocrinol. 2015;31(3):219-24.

59. Lu Z, Zhang W, Jiang S, Zou J, Li Y. Effect of lesion location on endometriotic adhesion and angiogenesis in SCID mice. Arch Gynecol Obstet. 2014;289(4):823-30
60. Ngô C, Chéreau C, Nicco C, Weill B, Chapron C, Batteux F. Reactive oxygen species controls endometriosis progression. Am J Pathol. 2009:175(1):225-34.

61. Birt JA, Taylor KH, Davis JW, Sharpe-Timms KL. Developmental exposure of fetal ovaries and fetal germ cells to endometriosis in an endometriosis model causes differential gene expression in the preimplantation embryos of the first-generation and second-generation embryos. Fertil Steril. 2013;100(5):1436-43.

62. Szymanowski K, Niepsuj-Biniaś J, Dera-Szymanowska A, WołuńCholewa M, Yantczenko A, Florek E, et al. An influence of immunomodulation on th1 and th2 immune response in endometriosis in an animal model. Biomed Res Int. 2013;2013.

63. Becker CM, Gattrell WT, Ph D, Gude K, Ph D. Reevaluating response and failure of medical treatment of endometriosis: a systematic review. Fertil Steril. 2017;108(1):125-36

64. Zulfikaroglu E, Islimye M, Aydin M, Zergeroglu S, Batioglu S. Efficacy of anti-tumor necrosis factor therapy on endometriosis in an experimental rat model. Arch Gynecol Obstetr. 2011;283(4):799-804.

65. Rudzitis-Auth J, Menger MD, Laschke MW. Resveratrol is a potent inhibitor of vascularization and cell proliferation in experimental endometriosis. Hum Reprod. 2013;28(5):1339-47.

66. Amaya SC, Savaris RF, Filipovic CJ, Wise JD, Hestermann E, Young $\mathrm{SL}$, et al. Resveratrol and endometrium: a closer look at an active ingredient of red wine using in vivo and in vitro models. Reprod Sci. 2014;21(11):1362-9.

67. Yavuz S, Aydin N, Celik O, Yilmaz E, Ozerol E, Tanbek K. Resveratrol successfully treats experimental endometriosis through modulation of oxidative stress and lipid peroxidation. J Cancer Res Ther. 2014;10(2):324.

68. Brasted M. Mimicking the Events of Menstruation in the Murine Uterus. Biol Reprod. 2003;69(4):1273-80.

69. Vercellini $\mathrm{P}$, Crosignani $\mathrm{P}$, Somigliana E, Vigan P, Frattaruolo MP, Fedele L. 'Waiting for Godot: a commonsense approach to the medical treatment of endometriosis. Hum Reprod. 2011;26(1):3-13.

70. Perrin S. Make mouse studies work. Nature. 2014;507(7493):423-5.

71. Prinz F, Schlange T, Asadullah K. Believe it or not: how much can we rely on published data on potential drug targets? Nat Rev Drug Discov. 2011;10(9):712-3.

72. Ioannidis JPA. Why most published research findings are false. PLoS Med. 2005;2(8):0696-701

73. Dong-xia Y, Wen-guang MA. Comparative study on the efficacy of yiweining gestrinone for post-operational treatment of stage endometriosis. Chin J Integr Med. 2006:12(3):218-20.

74. Vercellini P. Introduction Management of endometriosis: moving toward a problem-oriented and patient-centered approach. Fertil Steril. 2015;104(4):761-3.

75. Pullen N, Birch CL, Douglas GJ, Hussain Q, Pruimboom-Brees I, Walley RJ. The translational challenge in the development of new and effective therapies for endometriosis: a review of confidence from published preclinical efficacy studies. Hum Reprod Update. 2011;17(6):791-802.

76. Rogers PAW, Hooghe TMD, Fazleabas A, Gargett CE, Giudice LC, Montgomery GW, et al. Priorities for Endometriosis Research : Recommendations From an International Consensus Workshop. 2009;335-46.

77. American Society for Reproductive Medicine. Revised American Society for Reproductive Medicine classification of endometriosis: 1996. Fertil Steril. 1997;67:5

78. Giudice LC, Kao LC. Endometriosis. Lancet. 2004;364:1789-99.

79. Live DALO, Ritts ELAP. Treatment of Endometriosis. N Engl J Med. 2001;345(4):266-75

80. Wiegand KC, Shah SP, Al-Agha OM, Zhao Y, Tse K, Zeng T, et al. ARID1A mutations in endometriosis-associated. N Engl J Med. 2010;363(16):1532-43.

81. Ding S, Zhu L, Tian Y, Zhu T, Huang X, Zhang X. P2X3 receptor involvement in endometriosis pain via ERK signaling pathway. PLoS ONE. 2017:12(9):1-17.

82. Zondervan KT, Rahmioglu N, Morris AP, Dale R, Montgomery GW, Becker $\mathrm{CM}$, et al. Beyond endometriosis genome-wide association study: from genomics to phenomics to the patient. Semin Reprod Med. 2016:34(4):242-54.

83. Braza-Boïls A, Salloum-Asfar S, Marí-Alexandre J, Arroyo ABDS, GonzálezConejero R, Barceló-Molina M, et al. Peritoneal fluid modifies the 
microRNA expression profile in endometrial and endometriotic cells from women with endometriosis. Hum Reprod. 2015;30(10):2292-302.

84. Wright KR, Mitchell B, Santanam N. Redox regulation of microRNAs in endometriosis-associated pain. Redox Biol. 2017;12:956-66.

85. As-Sanie S, Kim J, Schmidt-Wilcke T, Sundgren PC, Clauw DJ, Napadow $V$, et al. Functional connectivity is associated with altered brain chemistry in women with endometriosis-associated chronic pelvic pain. J Pain 2016;17(1):1-13

86. Grundström H, Gerdle B, Alehagen S, Berterö C, Arendt-Nielsen L, Kjølhede $P$. Reduced pain thresholds and signs of sensitization in women with persistent pelvic pain and suspected endometriosis. Acta Obstet Gynecol Scand. 2018;98(3):327-36.

87. Zhao L, Gu C, Huang K, Han W, Fu M, Meng Y. Endometriosis research using capture microdissection techniques: progress and future applications (Review). Biomed Reports. 2016;5(5):531-40.

88. Backonja U, Louis GMB, Lauver DR. Overall Adiposity, Adipose Tissue Distribution, and Endometriosis: a Systematic Review. Nurs Res. 2016;65(2):151-66.

89. DeWan A, Liu M, Hartman S, Zhang SSM, Liu DTL, Zhao C, et al. HTRA1 promoter polymorphism in wet age-related macular degeneration. Science. 2006;314(5801):989-92.

90. Uimari O, Rahmioglu N, Nyholt DR, Vincent K, Missmer SA, Becker C, et al. Genome-wide genetic analyses highlight mitogen-activated protein kinase (MAPK) signaling in the pathogenesis of endometriosis. Hum Reprod. 2017;32(4):780-93.

91. Rahmioglu N, Nyholt DR, Morris AP, Missmer SA, Montgomery GW, Zondervan KT. Genetic variants underlying risk of endometriosis: insights from meta-analysis of eight genome-wide association and replication datasets. Hum Reprod Update. 2014;20(5):702-16.

92. Wang $Y$, Chen H, Wang NL, Guo HY, Fu Y, Xue S, et al. Combined $17 \beta$-estradiol with TCDD promotes M2 polarization of macrophages in the endometriotic milieu with aid of the interaction between endometrial stromal cells and macrophages. PLoS ONE. 2015;5(5):531-40.

93. Esfandiari N, Nazemian Z, Casper RF. Three-dimensional culture of endometrial cells: an in vitro model of endometriosis. Am J Reprod Immunol. 2008;60(4):283-9.

94. Duval K, Grover H, Han L-H, Mou Y, Pegoraro AF, Fredberg J, et al. Modeling physiological events in 2D vs. 3D cell culture. Physiology. 2017;32(4):266-77.

95. Riccio L, Santulli P, Marcellin L, Abrão MS, Batteux F, Chapron C. Immunology of endometriosis. Best Pract Res Clin Obstet Gynaecol. 2018:50:39-49.

96. Patel BG, Rudnicki M, Yu J, Shu Y, Taylor RN. Progesterone resistance in endometriosis: origins, consequences and interventions. Acta Obstet Gynecol Scand. 2017;96(6):623-32.

97. Liu T, Zhang L, Joo D, Sun S-C. NF-KB signaling in inflammation. Signal Transduct Target Ther. 2017;2(1):1-9.

98. Yua J, Berga SL, Zouc W, Taylora RN. Interleukin-1 $\beta$ Inhibits estrogen receptor-a, progesterone receptors $A$ and $B$ and biomarkers of human endometrial stromal cell differentiation: implications for endometriosis. Mol Hum Reprod. 2019;25(10):625-37.

99. Xu Z, Zhang L, Yu Q, Zhang Y, Yan L, Chen Z-J. The estrogen-regulated IncRNA H19/miR-216a-5p axis alters stromal cell invasion and migration via ACTA2 in endometriosis. Mol Hum Reprod. 2019;25(9):550-61.

100. Ichioka M, Mita S, Shimizu Y, Imada K, Kiyono T, Bono Y, et al. Dienogest, a synthetic progestin, down-regulates expression of CYP19A1 and inflammatory and neuroangiogenesis factors through progesterone receptor isoforms $A$ and $B$ in endometriotic cells. J Steroid Biochem Mol Biol. 2015;147:103-10. https://doi.org/10.1016/j.jsbmb.2014.12.008.

101. Shimizu Y, Mita S, Takeuchi T, Notsu T, Mizuguchi K, Kyo S. Dienogest, a synthetic progestin, inhibits prostaglandin E2 production and aromatase expression by human endometrial epithelial cells in a spheroid culture system. Steroids. 2011;76(1-2):60-7. https://doi.org/10.1016/j. steroids.2010.08.010.

102. Lang J, Yu Q, Zhang S, Li H, Gude K, Von Ludwig C, et al. Dienogest for treatment of endometriosis in Chinese women: a placebocontrolled, randomized, double-blind phase 3 study. J Women's Heal. 2018:27(2):148-55.

103. Altmäe S, Esteban FJ, Stavreus-Evers A, Simón C, Giudice L, Lessey $B A$, et al. Guidelines for the design, analysis and interpretation of "omics" data: focus on human endometrium. Hum Reprod Update. 2014;20(1):12-28.

104. Tamaresis JS, Irwin JC, Goldfien GA, Rabban JT, Burney RO, Nezhat C, et al. Molecular classification of endometriosis and disease stage using high-dimensional genomic data. Endocrinology. 2014;155(12):4986-99.

105. Denny JC, Bastarache L, Roden DM. Phenome-wide association studies as a tool to advance precision medicine. Annu Rev Genomics Hum Genet. 2016;31(17):353-73.

106. Rebholz-Schuhmann D, Oellrich A, Hoehndorf R. Text-mining solutions for biomedical research: enabling integrative biology. Nat Rev Genet. 2012;13(12):829-39.

107. Bouaziz J, Mashiach R, Cohen S, Kedem A, Baron A, Zajicek M, et al. How Artificial Intelligence Can Improve Our Understanding of the Genes Associated with Endometriosis: Natural Language Processing of the PubMed Database. Biomed Res Int.; 2018;2018:1-7. https:// www.hindawi.com/journals/bmri/2018/6217812/.

108. Lee JH, Kwon SY, Chang J, Yuk JS. Machine Learning Approach to fnd the relation between Endometriosis, benign breast disease, cystitis and non-toxic goiter. Sci Rep. 2019;9(1):1-7. https://doi.org/10.1038/ s41598-019-41973-w.

109. Boutros M, Heigwer F, Laufer C. Microscopy-based high-content screening. Cell. 2015;163(6):1314-25.

110. Godinez WJ, Hossain I, Lazic SE, Davies JW, Zhang X. A multi-scale convolutional neural network for phenotyping high-content cellular images. Bioinformatics. 2017;2017(33):2010-9.

111. Samala RK, Chan H, Hadjiiski LM, Helvie MA, Cha KH. Multi-task transfer learning deep convolutional neural network: application to computer-aided diagnosis of breast cancer on mammograms. Phys Med Biol. 2018;62(23):8894-908.

112. Kang G, Liu K, Hou B, Zhang N. 3D multi-view convolutional neural networks for lung nodule classification. PLOS ONE. 2017;12(11):e0188290.

113. Bouaziz J, Mashiach R, Cohen S, Kedem A, Baron A, Zajicek M, et al. How artificial intelligence can improve our understanding of the genes associated with endometriosis: natural language processing of the PubMed Database. Biomed Res Int. 2018;2018:1-7.

114. Gonçalves GA, Camargo-Kosugi CM, Bonetti TCS, Invitti AL, Girão MJBC, Silva IDCG, et al. p27kip1 overexpression regulates VEGF expression, cell proliferation and apoptosis in cell culture from eutopic endometrium of women with endometriosis. Apoptosis. 2015;20(3):327-35.

115. Lu X, Wu Y, Gao XH, Wang YW, Wang L, Sun XX. Effect of letrozole on estradiol production and P450 aromatase messenger RNA expression of cultured luteinized granulosa cells from women with and without endometriosis. Fertil Steril. 2012;98(1):131-5.

116. Fasciani A, Bocci G, Xu J, Bielecki R, Greenblatt E, Leyland N, et al. Threedimensional in vitro culture of endometrial explants mimics the early stages of endometriosis. Fertil Steril. 2003:80(5):1137-43.

117. Wang H, Pilla F, Anderson S, Martíednez-escribano S, Herrer I, Morenomoya JM, et al. A novel model of human implantation: 3D endometrium-like culture system to study attachment of human trophoblast (Jar) cell spheroids. Mol Hum Reprod. 2012;18(1):33-43.

118. Reardon S. Biodefence researchers seek "Homo chippiens". Nature. 2015;518(7539):285-6.

119. Baker M. Tissue models: a living system on a chip. Nature. 2011;471(7340):661-5.

120. Gnecco JS, Pensabene V, Li DJ, Ding T, Hui EE, Bruner-Tran KL, et al. Compartmentalized culture of perivascular stroma and endothelial cells in a microfluidic model of the human endometrium. Ann Biomed Eng. 2017:45(7):1758-69.

121. Xiao S, Coppeta JR, Rogers HB, Isenberg BC, Zhu J, Olalekan SA, et al. A microfluidic culture model of the human reproductive tract and 28-day menstrual cycle. Nat Commun. 2017;8:1-13. https://doi.org/10.1038/ ncomms 14584

122. Song KH, Highley CB, Rouff A, Burdick JA. Complex 3D-printed microchannels within cell-degradable hydrogels. Adv Funct Mater. 2018;28(31):1-10

123. Abbas MA, Taha MO, Zihlif MA, Disi AM. B-Caryophyllene causes regression of endometrial implants in a rat model of endometriosis without affecting fertility. Eur J Pharmacol. 2013. https://doi.org/10.1016/j.ejpha r.2013.01.011. 
124. Agostinis C, Zorzet S, De Leo R, Zauli G, De Seta F, Bulla R. The combination of $\mathrm{N}$-acetyl cysteine, alpha-lipoic acid, and bromelain shows high anti-inflammatory properties in novel in vivo and in vitro models of endometriosis. Mediators Inflamm. 2015. https://doi. org/10.1155/2015/918089.

125. Barretto AB, Siqueira JM, Denadai R. Evaluation of peritoneal endometriosis treatment using intralesional acetylsalicylic acid injection in rabbits. Orig Art Models Biol. 2016;31(4):227-34.

126. Bayoglu Tekin Y, Guven S, Kirbas A, Kalkan Y, Tumkaya L, Guvendag Guven ES. Is resveratrol a potential substitute for leuprolide acetate in experimental endometriosis? Eur J Obstet Gynecol Reprod Biol. 2015;184(2015):1-6. https://doi.org/10.1016/j.ejogrb.2014.10.041.

127. Bostanci MS, Bakacak M, Kizilkale OY, Yildirim G, Attar R, Özkan F, Inanc FT. Effects of aloe vera gel on the induction of endometriosis and regression of endometrial explants in a rat model. Clin Exp Obstet Gynecol. 2016;43(4):529-33.

128. Chen QH, Zhou WD, Pu DM, Huang QS, Li T, Chen QX. 15-Epi-lipoxin A4inhibits the progression of endometriosis in a murine model. Fertil Steril. 2010;93(5):1440-7. https://doi.org/10.1016/j.fertnstert 2009.01.107.

129. Efstathiou JA, Sampson DA, Levine Z, Rohan RM, Zurakowski D, Folkman J, et al. Nonsteroidal antiinflammatory drugs differentially suppress endometriosis in a murine model. Fertil Steril. 2005;83(1):171-81. https ://doi.org/10.1016/j.fertnstert.2004.06.058.

130. Elmali N, Ayan I, Turkoz Y, Mizrak B, Germen B, Bora A. Effect of caffeic acid phenethyl ester on cartilage in experimental osteoarthritis. Rheumatol Int. 2002;22(6):222-6. https://doi.org/10.1007/s0029 6-002-0232-9.

131. Güney M, Oral B, Karahan N, Mungan T. Regression of endometrial explants in a rat model of endometriosis treated with melatonin. Fertil Steril. 2008:89(4):934-42. https://doi.org/10.1016/j.fertnstert 2007.04.023.

132. Hull ML, Prentice A, Wang DY, Butt RP, Phillips SC, Smith SK, CharnockJones DS. Nimesulide, a COX-2 inhibitor, does not reduce lesion size or number in a nude mouse model of endometriosis. Hum Reprod. 2005;20(2):350-8. https://doi.org/10.1093/humrep/deh611.

133. Jana S, Paul S, Swarnakar S. Curcumin as anti-endometriotic agent: implication of MMP-3 and intrinsic apoptotic pathway. Biochem Pharmacol. 2012;83(6):797-804. https://doi.org/10.1016/j.bcp.2011.12.030

134. Kilico I, Kokcu A, Kefeli M, Kandemir B. Regression of experimentally induced endometriosis with a new selective cyclooxygenase-2 enzyme inhibitor. Gynecol Obstet Invest. 2014;77(1):35-9. https://doi. org/10.1159/000356686.

135. Kiykac Altinbas S, Tapisiz OL, Cavkaytar S, Simsek G, Oguztuzun S, Goktolga U. Is montelukast effective in regression of endometrial implants in an experimentally induced endometriosis model in rats? Eur J Obstet Gynecol Reprod Biol. 2015;184(2015):7-12. https://doi.org/10.1016/j. ejogrb.2014.10.026.

136. Kizilay G, Uz YH, Seren G, Ulucam E, Yilmaz A, Cukur Z, Kayisli UA. In vivo effects of curcumin and deferoxamine in experimental endometriosis. Adv Clin Exp Med. 2017;26(2):207-13. https://doi.org/10.17219/ acem/31186.

137. Kurt RK, Pinar N, Karateke A, Okyay AG, Silfeler DB, Albayrak A, et al. Protective effects of colchicine in an experimental rat endometriosis model: histopathological evaluation and assessment of TNF-alpha levels. Reprod Sci. 2015;22(2):258-63.

138. Laux-Biehlmann A, Boyken J, Dahllöf H, Schmidt N, Zollner TM, Nagel J. Dynamic weight bearing as a non-reflexive method for the measurement of abdominal pain in mice. Eur J Pain. 2016;20(5):742-52. https:// doi.org/10.1002/ejp.800.

139. Machado DE, Berardo PT, Landgraf RG, Fernandes PD, Palmero C, Alves LM, et al. A selective cyclooxygenase-2 inhibitor suppresses the growth of endometriosis with an antiangiogenic effect in a rat model. Fertil Steril. 2010;93(8):2674-9. https://doi.org/10.1016/j.fertnstert 2009.11.037.

140. Matsuzaki S, Canis M, Darcha C, Dallel R, Okamura K, Mage G. Cyclooxygenase-2 selective inhibitor prevents implantation of eutopic endometrium to ectopic sites in rats. Fertil Steril. 2004;82(6):1609-15. https://doi. org/10.1016/j.fertnstert.2004.07.946.

141. Nenicu A, Gu Y, Körbel C, Menger MD, Laschke MW. Combination therapy with telmisartan and parecoxib induces regression of endometriotic lesions. Br J Pharmacol. 2017;174(16):2623-35. https://doi. org/10.1111/bph.13874.

142. Neto JN, Coelho TM, Aguiar GC, Carvalho LR, De Araújo AGP, Girão MJBC, Schor E. Experimental endometriosis reduction in rats treated with Uncaria tomentosa (cat's claw) extract. Eur J Obstet Gynecol Reprod Biol. 2011;154(2):205-8. https://doi.org/10.1016/j.ejogr b.2010.10.002.

143. Neto JN, Cavalcante FLLP, Carvalho RAF, Rodrigues TGPDM, Xavier MS, Furtado PGR, Schor E. Contraceptive effect of Uncaria tomentosa (cat's claw) in rats with experimental endometriosis. Acta cirurgica Brasileira. 2011;26:15-9.

144. Olivares C, Ricci A, Bilotas M, Barañao Rl, Meresman G. The inhibitory effect of celecoxib and rosiglitazone on experimental endometriosis. Fertil Steril. 2011;96(2):428-33. https://doi.org/10.1016/j.fertnstert .2011.05.063.

145. Qu F, Zhou J, Ma B. The effect of Chinese herbs on the cytokines of rats with endometriosis. J Alt Compl Med. 2005;11(4):627-30. https://doi. org/10.1089/acm.2005.11.627.

146. Saltan G, Süntar I, Ozbilgin S, Ilhan M, Demirel MA, Oz BE, et al. Viburnum opulus $L .:$ A remedy for the treatment of endometriosis demonstrated by rat model of surgically-induced endometriosis. J Ethnopharmacol. 2016;193:450-5. https://doi.org/10.1016/j.jep.2016.09.029.

147. Siqueira JM, Barreto AB, Saad-Hossne R. Treatment of endometriosis with local acetylsalicylic acid injection: experimental study in rabbits. J Minim Invas Gynecol. 2011;18(6):800-6. https://doi.org/10.1016/j. jmig.2011.08.721.

148. Soylu Karapinar O, Pinar N, Özgür T, Özcan O, Bayraktar HS, Kurt RK, Nural O. The protective role of dexpanthenol on the endometrial implants in an experimentally induced rat endometriosis model. Reprod Sci. 2017;24(2):285-90. https://doi.org/10.1177/1933719116 653682.

149. Sun X, Chen L, Zeng F. Effects of Chinese materia medica-fubao danggui jiao on experimental endometriosis. Afr J Tradit Complement Altern Med. 2011;8(3):224-9.

150. Takai E, Taniguchi F, Nakamura K, Uegaki T, Iwabe T, Harada T. Parthenolide reduces cell proliferation and prostaglandin estradiol synthesis in human endometriotic stromal cells and inhibits development of endometriosis in the murine model. Fertil Steril. 2013;100(4):1170-8. https://doi.org/10.1016/j.fertnstert.2013.06.028.

151. Xiao YH, Chen DP, Yan JH, Yokoyama Y. Mechanism of action of Tripterygium Wilfordii polyglycoside on experimental endometriosis. Eur J Gynaecol Oncol. 2002;23(1):63-7.

152. Zhou ZH, Weng Q, Zhou JH, Zhou J. Extracts of salvia miltiorrhiza bunge on the cytokines of rat endometriosis models. Afr J Tradit Complement Altern Med. 2012;9(3):303-14.

\section{Publisher's Note}

Springer Nature remains neutral with regard to jurisdictional claims in published maps and institutional affiliations. 